\title{
PROBLEMÁTICA JURÍDICA SOBRE LA DELIMITACIÓN DE LOS ESPACIOS MARÍTIMOS DEL ARCHIPIÉLAGO CANARIO (A PROPÓSITO DE LA LEY 44/2010)
}

VICENTE J. NAVARRO MARCHANTE 


\section{SUMARIO}

I. INTRODUCCIÓN AL CONCEPTO DE TERRITORIO COMO ELEMENTO DEL ESTADO. II. DELIMITACIÓN CONCEPTUAL DE LOS ESPACIOS MARÍTIMOS. III. LAS PECULIARIDADES DE LA DELIMITACIÓN DE LOS ESPACIOS MARÍTIMOS DE ISLAS Y ARCHIPIÉLAGOS: LAS SINGULARIDADES DE CANARIAS. III.1 El espacio marítimo interinsular de los Estados Archipielágicos y de los Archipiélagos de Estado. III.2. La problemática específica de delimitación de los espacios marítimos de las Islas Canarias. III.3. La situación de otros Archipiélagos de Estado en Derecho Comparado. III.4. Los problemas de delimitación de otros espacios marítimos en torno a Canarias: a) La delimitación con Marruecos, b) La delimitación con las Islas portuguesas. III.5. Propuestas recientes en torno a los problemas de delimitación de los espacios marítimos de Canarias. La Ley 44/2010. IV. CONCLUSIONES. Bibliografía. 


\title{
PROBLEMÁTICA JURÍDICA SOBRE LA DELIMITACIÓN DE LOS ESPACIOS MARÍTIMOS DEL ARCHIPIÉLAGO CANARIO (A PROPÓSITO DE LA LEY $44 / 2010)$
}

\author{
POR \\ VICENTE J. NAVARRO MARCHANTE \\ Profesor Ayudante Doctor de Derecho Constitucional \\ Universidad de La Laguna
}

\section{INTRODUCCIÓN}

Las Cortes Generales han aprobado la Ley 44/2010, de 30 de diciembre, de Aguas Canarias (BOE no 318 de 31 de diciembre de 2010)ํㅜㄹ que entrará en vigor a los tres meses de su publicación en el BOE (según prevé la disposición final segunda de la Ley $)^{2}$. La nueva establece que las aguas interinsulares que hay entre

${ }^{1}$ Este trabajo ha sido elaborado antes de la aprobación de la Ley 44/2010, no obstante, antes de la publicación del artículo, se han introducido de forma urgente algunas referencias al nuevo texto legal.

${ }^{2}$ Este texto legal ha sido fruto de un pacto político entre el PSOE y Coalición Canaria por el que la formación nacionalista se comprometía a apoyar los Presupuesto Generales del Estado para 2011 y, como contrapartida, el PSOE asumía, de forma pública y por escrito, una serie de compromisos, entre ellos el de apoyar una proposición de ley de Coalición Canaria, admitida a trámite el pasado 15 de diciembre de 2009 por unanimidad de todos los diputados presentes, relativa a la consideración de las aguas interinsulares de las Islas Canarias como aguas canarias. 
las islas e islotes de Canarias (delimitadas por un perímetro de líneas rectas que unen los puntos más salientes de las diferentes Islas, según se especifica de forma descriptiva en el Anexo 1 de la Ley y de forma gráfica en el Anexo 2) se denominarán «aguas canarias y constituyen el especial ámbito marítimo de la Comunidad Autónoma de Canarias» (apartado 1 de su artículo único).

Esta circunstancia vuelve a poner sobre la mesa el debate en torno a los problemas de delimitación jurídica de las aguas marítimas y territorio submarino en torno a las Islas Canarias. Además, hay que recordar que sigue pendiente la nueva reforma del Estatuto de Autonomía de Canarias ${ }^{3}$ donde uno de los principales problemas que se prevé es que se planteará la consideración de las aguas interinsulares como territorio propio de la Comunidad Autónoma ${ }^{4}$, atendiendo a que es contenido necesario del Estatuto de Autonomía el delimitar su territorio (art. 147.2.b) $\mathrm{CE}$ ). En este trabajo pretendemos analizar esos problemas jurídicos, que combinan factores de Derecho Constitucional español y de Derecho Internacional Público.

\section{INTRODUCCIÓN AL CONCEPTO DE TERRITORIO COMO ELEMENTO DEL ESTADO}

La disciplina del Derecho Constitucional, como puede comprobarse en cualquier temario o manual de la asignatura, toma como uno de sus primeros objetivos la definición y análisis del Estado, como forma jurídico política inseparable del concepto de Constitución. Al tratar los elementos configuradores del Estado, siempre se hace necesaria una referencia al territorio, junto a otros como el pueblo y el poder o el Derecho y alguna referencia a los autores clásicos sobre Teoría del Estado como Hauriou, Carré de Malberg, Kelsen o Jellinek. No obstante, nuestra disciplina en España, en las últimas décadas, ha ido marginando poco a poco el análisis de estos temas por diferentes razones 5 .

${ }^{3}$ Véase la proposición de ley del Parlamento de Canarias presentada en las Cortes Generales en Boletín Oficial de las Cortes Generales de 22 de septiembre de 2006 y que fue finalmente retirada por el legislativo autonómico, donde su art. 3.1 decía «El ámbito territorial de la Comunidad Autónoma de Canarias comprende el archipiélago canario, integrado por las siete islas de El Hierro, Fuerteventura (...), por el mar que las conecta y por el espacio aéreo correspondiente».

${ }^{4}$ Este previsible escollo en la aprobación del texto estatutario canario en las Cortes Generales es incluso destacado por los diarios de información general, así véase diario El País de 16 de abril de 2010, en cuya información titulada «El catalán marcó el camino de otros ocho estatutos» se dice que el texto de reforma estatutaria enviado por Canarias «iba mucho más allá que el catalán en algunas cosas y presenta elementos de dudosa constitucionalidad (...) como considerar parte del territorio de la comunidad las aguas jurisdiccionales».

${ }^{5}$ Entre ellas, la aparición de la Constitución de 1978 y su desarrollo posterior, que ha ido en- 
Las posiciones doctrinales en torno al territorio como elemento esencial o constitutivo del Estado pueden agruparse, en resumen, en diversas teorías:

El territorio como objeto del poder del Estado. Estas ideas sostienen que el Estado tiene una especie de derecho real de propiedad sobre el territorio que le facultaría para disponer del mismo y para excluir la actuación de cualquier otro Estado sobre él ${ }^{6}$. Sin embargo, se puede objetar, como por ejemplo Díaz Nieva $(1997,28)$, que si el territorio es un elemento constitutivo para el Estado, esta teoría que diferencia entre sujeto (Estado) y objeto (territorio) no sería aceptable, y recuerda que Carrè de Malberg señalaba que el territorio del Estado «es un elemento de su ser y no de su haber».

El territorio como parte integrante de la personalidad del Estado. De esta forma, el Estado tendría sobre su territorio un derecho semejante al que la persona tiene sobre su cuerpo, lo que supone una relación entre ambos más íntima que la pura y simple que se crea en el derecho de propiedad, de modo que la violación del territorio supondría una violación del Estado mismo ${ }^{7}$. Para Tenorio Sánchez $(1993,21)$ esta teoría no acierta a explicar por qué el Estado puede llegar a disponer del territorio; y para Sánchez Ferriz $(2009,155)$ esta teoría sólo puede formularse con una condición previa implícita: la del reconocimiento de la personalidad del Estado.

El Estado ejerce indirectamente un dominio sobre el territorio a través del elemento humano. Para Jellinek (2000, 368 y ss.): «Jamás puede, pues, el Estado directamente, sino por la mediación de sus súbditos, ejercer dominio sobre el territorio. El dominio directo jurídico sobre una cosa, dominio que se exterioriza por acciones físicas sobre la misma, es lo que constituye la propiedad. El dominio sobre el territorio no es, desde el punto de vista del Derecho Público, dominium, sino imperium. El imperium significa poder de mando, mas este poder sólo es referible a los hombres». Y añade que una cosa sólo puede estar sometida al imperium siempre que

grosando la materia de forma sensible. Quizá también el abandono del viejo Derecho Político y, en consecuencia, de ciertos temas comunes de Teoría del Estado a favor de la Ciencia Política. De hecho, salvo las referencias más o menos amplias al territorio en el tema correspondiente de algunos manuales, la doctrina constitucional española ha dedicado escasos esfuerzos a esta materia.

${ }^{6}$ En Alemania, los autores comprometidos con la apologética monárquica (justificadores del llamado «principio monárquico»), como Laband o Gerber, conciben la relación Estado-territorio inspirándose en el derecho de propiedad que ostentaba el Príncipe en el Estado patrimonial, tesis criticada en su momento por Kelsen, 2002, 230 y que, entre nosotros, vuelve a recordar Alzaga, (2007, 182). Por su parte, Santamaría Pastor $(2001,96)$ critica que el art. 132.2 de nuestra Constitución, probablemente con otra pretensión del constituyente (establecer el dominio público, no apropiable), se refiere a la zona marítimo terrestre y otras casi como a «propiedades administrativas, forzándonos a evocar las primeras tesis alemanas».

${ }^{7}$ Véase cita de Preuss realizada por Jellinek (2000, 371). 
«el poder del Estado ordene a los hombres obrar de una cierta manera con respecto a ella», por tanto, el derecho al territorio sería «un reflejo de la dominación sobre las personas, es decir, es un derecho reflejo, no un derecho en sentido subjetivo». También resulta pertinente recordar que Jellinek se ocupaba de que la significación jurídica del territorio del Estado tenía una vertiente negativa, de impenetrabilidad, en tanto que se prohíbe a cualquier otro poder no sometido al del Estado el ejercer funciones de autoridad en el territorio sin autorización expresa.

El territorio como espacio de validez del orden jurídico del Estado, para Kel$\operatorname{sen}^{8}(2002,229$ y ss.) la relación del Estado (titular del poder jurídico soberano) con su territorio no es una relación jurídica real ni personal: «Los hechos o situaciones que constituyen el contenido de la norma tienen que ser estudiados como vigentes en un determinado lugar y en un determinado tiempo, pues de lo contrario la norma no estaría vigente en ningún lugar ni en ningún tiempo, lo que equivaldría a decir que carece pura y simplemente de vigencia. Una norma que no vale para ningún tiempo ni espacio, es una norma que carece en absoluto de vigencia» ${ }^{9}$. El propio Kelsen se referirá al carácter tridimensional del territorio, referido a tierra, mar y aire, y de lo que nos ocuparemos en las siguientes páginas.

Para Sánchez Ferriz $(2009,156)$ el territorio puede verse desde otra perspectiva y así recuerda que Burdeau afirmaba que «no es que el territorio sea un elemento constitutivo del Estado sino que es una condición indispensable para que la autoridad política se ejerza eficazmente» en tanto que el territorio es a la vez marco de competencia (en tanto que determina la esfera de autonomía de cada Estado en el ámbito internacional) y medio de acción del Estado, soporte material de su autoridad o instrumento de poder, porque quien tiene el suelo tiene al habitante (cuando el hombre no puede escapar a la acción de los gobernantes mas que dejando la tierra que le nutre su vulnerabilidad es mayor). Torres del Moral (2004, 32 y ss.) prefiere hablar de que el Estado tiene elementos materiales (población y territorio) y formales (poder y Derecho).

También conviene recordar las advertencias de Kriele $(1980,125)$ en el sentido de que el territorio del Estado debe ser delimitado conforme al Derecho,

${ }^{8}$ Santamaría Pastor $(2001,96)$ recuerda que la formulación inicial de esta idea corresponde a Fricker, que calificaba al territorio como «límite geográfico del Derecho del Estado», luego recogida por Radnitzky y finalmente por Kelsen.

${ }^{9}$ Alzaga $(2007,83)$ matiza que Kelsen se refiere al ámbito de validez, que no de eficacia, del orden estatal «en efecto, en un lugar situado fuera del territorio, en un espacio ilimitado se pueden realizar de hecho actos por el Estado, pero ello no es razón suficiente para que tal lugar pase a integrar el territorio del aquel Estado que, de hecho, pero contraviniendo el Derecho internacional, ha cometido el acto de poder con extralimitación espacial». 
huyendo de supuestas teorías de fijación de los límites en virtud de ideas como las de «fronteras naturales»o, quizá peor aún, por el lebensraum o «espacio vital» de un pueblo, que sabemos a qué tipo de conflictos con los Estados vecinos nos puede llevar.

\section{DELIMITACIÓN CONCEPTUAL DE LOS ESPACIOS MARÍTIMOS}

Señalábamos anteriormente que ya Kelsen insistía en que el territorio, como elemento del Estado, es una realidad tridimensional que incluye tierra (superficial y subsuelo), agua (tanto continentales como marítimas) y espacio aéreo ${ }^{10}$. Refiriéndonos a cualquiera de los tres elementos, podríamos encontrar problemas de delimitación entre Estados fronterizos.

A los efectos de lo que aquí pretendemos, resulta pertinente, aún a riesgo de parecer descriptivo, el fijar con precisión el concepto, régimen jurídico y delimitación general de cada una de las categorías de espacios marítimos que luego pretendemos utilizar con precisión al aplicarlo a la realidad del Archipiélago canario; se debe tener en cuenta que, aún con frecuencia, se suelen utilizar términos como «aguas jurisdiccionales», «aguas territoriales» o «aguas soberanas» que son términos con cierto grado de imprecisión técnica jurídica.

El Estado ribereño ha tenido un creciente interés por ampliar su dominio sobre el espacio marítimo adyacente a su costa, inicialmente por razones de seguridad y más tarde por apropiarse de los diferentes recursos que ofrece, junto a otras razones como control del tráfico marítimo cerca de sus costas ${ }^{11}$. Como es fácilmente deducible, esta situación genera graves tensiones en la Sociedad Internacional donde habrá numerosos conflictos de intereses contrapuestos entre Es-

\footnotetext{
${ }^{10}$ Santamaría Pastor $(2001,95)$ sólo admite la tierra firme como único territorio en sentido jurídico pleno y estricto, puesto que la soberanía que se ejerce sobre el mar o espacio aéreo esta limitada por la técnica y por el Derecho Internacional, que permite «a los restantes Estados una serie de utilización muy amplias (...). No concurren en estos espacios, pues, dos de las notas que la doctrina internacionalista predica del concepto de territorio, como son la plenitud y la exclusividad». Hay que tener en cuenta que el texto de Santamaría Pastor, aunque publicado en 2001 y originalmente en otra obra en 1995, sólo se refiere a los Convenios de Ginebra de 1958 y 1960 y no menciona nada del Convenio de Montego Bay de 1982.

${ }^{11}$ El Derecho del Mar clásico, desde finales del siglo XVII, establecía el principio de libertad de los mares y se calificaba al mar como res communis omnium, cuya propia naturaleza impedía que fuera objeto de ocupación y posesión. La soberanía estatal sólo se aplicaba a las reducidas aguas interiores y a una pequeña franja de mar territorial. Para un breve acercamiento histórico a la cuestión véase Martín Ruiz (2005, 1 a 3) que, entre otros, analiza el debate entre Grocio y su obra Mare Liberum (1609) y la réplica de Selden con Mare Clausum (1635).
} 
tados fronterizos, pero también entre Estados ribereños partidarios de ampliar sus aguas y potencias marítimas partidarias de la libertad de mares. A partir de la creación de la ONU ha habido varias Conferencias sobre Derecho del Mar, las dos primeras en Ginebra en 1958 y 1960 y la tercera, desde 1973 hasta 1982, que concluyó con el Convenio de las Naciones Unidas sobre Derecho del Mar aprobada en Montego Bay, Jamaica ${ }^{12}$. Este Convenio, recopilando el ordenamiento jurídico internacional anterior, funciona ahora a modo de código internacional de derecho del mar, fijando su régimen jurídico básico. El control de la aplicación del Convenio se encomienda, entre otros, a un nuevo órgano jurisdiccional permanente y especializado, el Tribunal Internacional del Derecho del Mar, con sede en Hamburgo y operativo desde 1996.

Este Convenio de $1982^{13}$, en función de los diferentes derechos que el Estado puede desplegar sobre los espacios marítimos adyacentes ${ }^{14}$, establece las siguientes categorías ${ }^{15}$ :

\section{a) Aguas interiores.}

Son las aguas marinas, o no continentales, que tienen su límite interior en tierra firme y el límite exterior en el inicio del mar territorial. Es una extensión del territorio que afecta a las aguas de puertos, bahías y estuarios, o las delimitadas mediante una línea de base recta entre dos puntos salientes de la $\operatorname{costa}^{16} \mathrm{o}$ desde una franja de islas en su proximidad inmediata, es decir, aguas estrechamente ligadas y subordinadas al dominio terrestre; en ellas el Estado puede reservar la pesca a favor de sus nacionales y la navegación de buques de su bande-

${ }^{12}$ Entre nosotros, ofrece un tratamiento amplio y detallado de este Convenio Yturriaga Barberán (1993) que participó en la delegación española.

${ }^{13}$ La Convención de 1982 entró en vigor el 16 de noviembre de 1994, un año después de recibir su $60^{a}$ ratificación. España no suscribió el Convenio inmediatamente, lo firmó el 5 de diciembre de 1984, ratificándolo mediante instrumento el 20 de diciembre de 1996, depositado ante Naciones Unidas el 15 de enero de 1997. Se publicó en los BOE n 38 y 39 de 13 y 14 de febrero de 1997 y entró en vigor para nuestro país este último día.

${ }^{14}$ Este Convenio estableció que el $40 \%$ del océano quedara bajo algún tipo de control por parte del algún Estado ribereño concreto.

${ }^{15}$ Para un tratamiento amplio y sistemático de todas estas categorías véase, entre la bibliografía más reciente, a Díez de Velasco (2009, 475 y ss.) o Pulido Begines (2009, 101 y ss.).

${ }^{16}$ Las líneas de base rectas salvan escotaduras y aberturas de la costa de acuerdo con lo previsto en el Convenio de Ginebra de 1958 según los criterios que fijó la Corte Internacional de Justicia en la Sentencia de 18 de diciembre de 1951 en el caso de las pesquerías anglo-noruegas. 
ra (navegación de cabotaje) ${ }^{17}$ e incluso rehusar el acceso a los buques extranjeros, excepto en caso de peligro, por lo que ejerce todas sus competencias casi sin limitaciones. Será el Estado ribereño, con ciertos requisitos, el que determine la delimitación de esas aguas, lo que, a juicio de Pulido Begines $(2009,102)$ o Lacleta Muñoz $(2003,3)$ suele ser motivo de abuso.

La norma nacional española que hace la delimitación es la Ley 10/1977, de 4 de enero, sobre el mar territorial (BOE $\mathrm{n}^{\circ} 7$ de 8 de enero); también hay que tener en cuenta el RD 2.510/1977, de 5 de agosto (BOE no 234 de 30 de septiembre), sobre trazado de líneas de base rectas, que, en lo referente a Canarias, engloba al conjunto formado por las islas de Lanzarote y Fuerteventura, con sus respectivos islotes, dentro de un perímetro común, y prevé algunas líneas de base rectas entre puntos salientes de la costa de cada Isla, no de una Isla a otra, en todas las demás a excepción de La Gomera donde no se prevé ninguna.

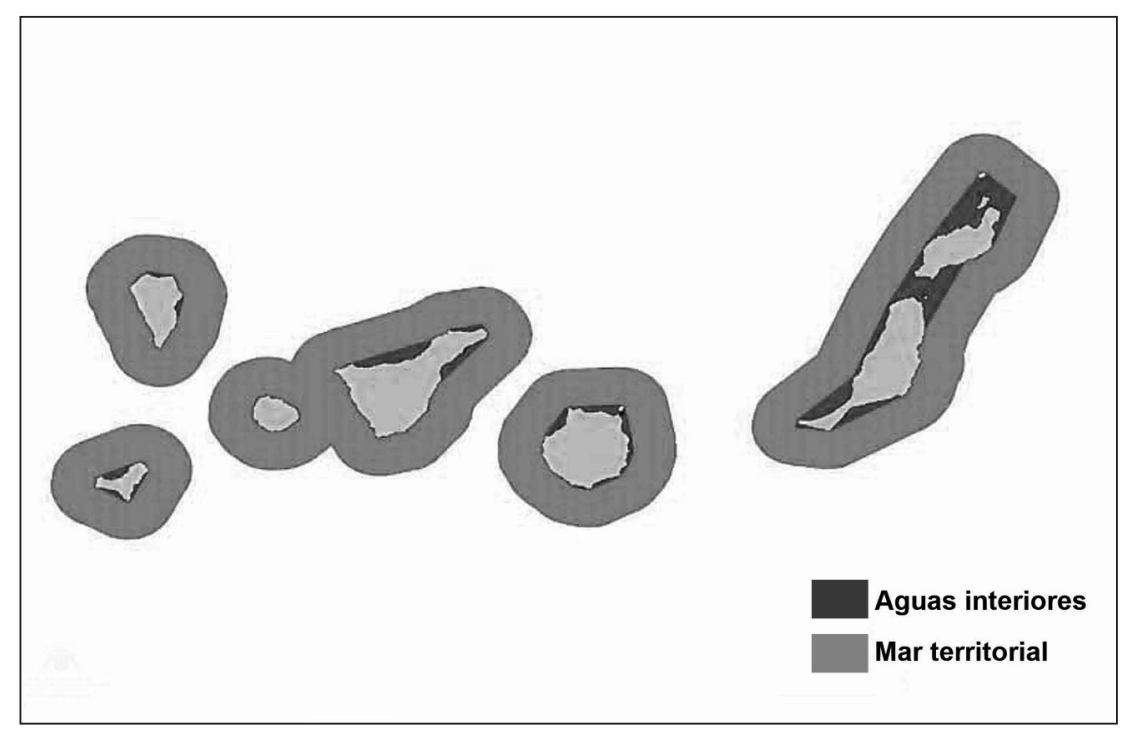

FUENTE: ELABORACIÓN PROPIA.

${ }^{17}$ En el seno de la Unión Europea, en línea con la política comunitaria de liberalización de los transportes y fomentar la libre competencia entre las empresas navieras, se ha establecido el principio de libre prestación de esos servicios para buques de la Unión, así, en España, el RD $1516 / 2007$. 


\section{b) El mar territorial.}

Es la franja de mar adyacente al Estado ribereño y que se extiende a partir de su territorio (línea de base a contar desde la bajamar a lo largo de la costa o, en su caso, desde el límite externo de las aguas interiores calculado por las líneas de base recta), hasta una extensión máxima de doce millas ${ }^{18}$. En esa zona el Estado proyecta su soberanía, aunque con ciertas restricciones. Una de ellas es permitir el derecho de paso inocente y gratuito (en virtud del principio de libertad de comercio y navegación) que incluye la navegación lateral, de paso o tránsito, y perpendicular, de entrada o salida, por dicho mar, debiendo ser el paso rápido e ininterrumpido, abarcando también el derecho a detenerse y fondear en tanto que incidentes normales impuestos por la navegación o a causa de fuerza mayor (arts. 2 a 32 Convenio de 1982). También existen ciertas limitaciones al Estado ribereño en el ejercicio de su jurisdicción civil y penal sobre buques extranjeros especificadas en el Convenio.

La Ley española (art. 4 de la Ley 10/1977) acude al criterio de la delimitación convencional del mar territorial español para los casos de existencia de otros Estados próximos con mar adyacente ${ }^{19}$ y que implique una necesaria reducción de las 12 millas. El Convenio de 1982 prevé que, en estos casos, se alcance un pacto entre los interesados y, en su defecto, que se aplique el criterio de la equidistancia.

\section{c) La zona contigua.}

Es una franja que se sitúa a continuación del límite exterior del mar territorial y en la que el Estado ribereño puede tomar una serie de medidas específicas

\footnotetext{
${ }^{18}$ Las doce millas ya habían sido establecidas por el Convenio de Ginebra de 1958 y la legislación española posterior así lo recogía primero en la Ley 20/1967, de 8 de abril, sobre extensión de las aguas jurisdiccionales españolas a doce millas, a efectos de pesca (BOE $n^{\circ} 283$ de 25 de noviembre) y posteriormente en la Ley 10/1977. Una milla marina tiene una longitud de 1.851,83 metros, por lo que la franja tiene 22.222 metros.

${ }^{19}$ Existen diversos Convenios bilaterales suscritos por España con sus vecinos, a los efectos de los que aquí interesa, recordaremos que los dos Convenios de Guarda con Portugal de 1976 sobre delimitación tanto del mar territorial y la zona contigua como de la plataforma continental, que respetan el principio de equidistancia, no han sido ratificados por la falta de acuerdo sobre la delimitación de la plataforma continental y la zona exclusiva entre Canarias y Madeira, aunque de facto ambos Estados lo respetan. No hay convenio delimitador con Marruecos, aunque, nuevamente de facto, se viene utilizando el criterio de la equidistancia.
} 
en materia aduanera, fiscal, sanitaria y de inmigración. Para todo lo demás su régimen jurídico será el que luego veremos para la zona económica exclusiva. Se trata de permitir mayor eficacia para que el Estado ribereño pueda prevenir y sancionar las infracciones de sus disposiciones cometidas en su territorio (incluido el mar territorial) en las materias tasadas mencionadas (incluyendo también control sobre los restos arqueológicos e históricos), una especia de derecho de persecución de buques extranjeros más allá del límite del mar territorial. Su anchura no podrá extenderse más allá de 24 millas marinas contadas desde las líneas de base desde las cuales se mide la anchura del mar territorial. Téngase en cuenta que, en condiciones normales, las primeras doce millas serán de mar territorial y las siguientes doce (en total 24) son estrictamente las de zona contigua. España no reguló esa zona en la Ley 10/1977, su régimen vigente se encuentra en la Ley 27/1992, de 22 de noviembre, de Puertos del Estado y de la Marina Mercante (BOE n 283 de 25 de noviembre).

\section{d) La zona económica exclusiva.}

Es la zona, adyacente al mar territorial, que se prolonga hasta un máximo de 200 millas, contadas desde las líneas de base desde las cuales se mide la anchura del mar territorial ${ }^{20}$, en la que el Estado ribereño tiene el derecho exclusivo de explotación de los recursos económicos en ese espacio marino (agua, lecho y subsuelo marino), vivos o no vivos. Podría decirse que es una especie de «soberanía económica», en todo lo demás rige el régimen aplicable a la alta mar. El régimen nacional español sobre este espacio se recoge en la Ley 15/1978, de 20 de febrero, sobre Zona Económica (BOE n ${ }^{\circ} 46 / 1978$, de 23 de febrero) ${ }^{21}$, que, aunque previa al Convenio de 1982, también establecía el régimen de 200 millas $^{22}$. No

${ }^{20}$ Téngase en cuenta que, en condiciones normales, las primeras doce millas serán de mar territorial y las siguientes 188 (en total 200) son estrictamente las de zona económica exclusiva, sabiendo que entre la 12 y las 24 está la zona contigua que para ciertas cuestiones tiene su propio régimen jurídico y para las demás se aplica el régimen de la ZEE.

${ }^{21}$ La Disposición Final Primera de esta norma prevé que la ZEE española de 200 millas se aplique solamente a las costas españolas, peninsulares e insulares, del Atlántico, aunque el Gobierno queda facultado para extenderlo a otras; así, para el Mediterráneo, véase el RD 1.315/1997 por el que se establece una zona de protección pesquera en el mar Mediterráneo y que afectaría a Baleares.

${ }^{22}$ Tras la adhesión de España a la Comunidad Europea nuestra zona económica exclusiva se encuentra plenamente sometida a la llamada política común pesquera. Así, entre las 12 y las 200 millas de aguas de los Estados miembros rige el principio básico de libre acceso de los pesqueros de cualquier otro Estado miembro sin discriminación y los acuerdos entre la Comunidad y terceros Estados. 
obstante, luego veremos que preveía un sistema de delimitación de la zona en el caso del Archipiélago de Canarias que no quedará recogido de la misma forma en el Convenio de Montego Bay de 1982.

\section{e) Plataforma continental.}

El Convenio del Mar de 1958, recogiendo las demandas de los Estados ribereños respecto a los recursos del lecho y subsuelo de sus plataformas continentales, aceptó que los Estados las estableciesen teniendo en cuenta ciertos requisitos de profundidad y explotabilidad, sin una limitación concreta. Sin embargo, el Convenio de 1982, para simplificar el régimen, la ha limitado a 200 millas, haya o no plataforma geológica, haciéndola coincidir con la zona económica exclusiva (por lo que, en la mayoría de los casos pierde su razón de ser, así ocurre para España donde la plataforma es inferior a 200 millas en la mayoría de los $\operatorname{casos}^{23}$ ), pero permitiendo que los países con amplia plataforma geológica y con derechos adquiridos respecto a la anterior normativa la amplíen hasta el límite real de la misma $^{24}$. Los recursos sobre los que el Estado ribereño tiene derecho de aprovechamiento exclusivo son los no vivos y los vivos de especies sedentarias que mantengan contacto físico con el lecho de la plataforma. No afecta, por tanto, al régimen de las aguas suprayacentes ni espacio aéreo sobre esas aguas.

Para la delimitación de la plataforma y de la zona económica exclusiva entre Estados ribereños vecinos, el Convenio de 1982 insta a solucionar las posibles discrepancias que surjan buscando una «solución equitativa» mediante la aplicación de los principios de Derecho Internacional (negociación de buena fe, teniendo en cuenta las circunstancias y factores relevantes — geográficas, geológicas, socioeconómicas, poblacionales, etc.-, manteniendo la congruencia de los actos propios, etc.), en consecuencia, hay una cierta pérdida de protagonismo de la simple aplicación matemática de regla de la equidistancia.

Según recuerdan Lacleta, Almazán y Estepa $(2009,104)$, «podemos afirmar que España necesita, si distinguimos las delimitaciones del mar territorial de las correspondientes a la plataforma continental o a la zona económica exclusiva,

\footnotetext{
${ }^{23}$ No obstante, señala Ruiloba García $(2009$, 492) que «el Gobierno ha procedido recientemente a solicitar la extensión de la plataforma continental de Canarias hacia el oeste más allá de las 200 millas, ante la Comisión de Límites de la Plataforma Continental, de acuerdo con lo dispuesto en el art. 76 de la Convención de las Naciones Unidas de 1982 sobre Derecho del Mar».

${ }^{24}$ Brasil ya está explotando yacimientos de petróleo a 300 millas de su costa, véase diario El Día del 9 de enero de 2010.
} 
unos 22 acuerdos de delimitación. De ellos, en este momento, no se encuentran en vigor más que los correspondientes al mar territorial en el golfo de Vizcaya respecto de Francia; al mar territorial en el Atlántico respecto a Portugal en la desembocadura del Miño; y a la plataforma continental entre Menorca y Cerdeก̃a».

La ONU, en virtud de lo dispuesto en el art. 76 del Convenio de 1982, ha acordado atender las demandas de los Estados ribereños de ampliar la plataforma más allá de las 200 millas de ZEE que sean realizadas antes de 2014. Por este motivo, España está realizando estudios oceanográficos en las costas cántabras, gallegas y canarias $^{25}$; están realizando trabajos similares Canadá, Argentina o Chile y, dentro de la Unión Europea, Francia, Reino Unido e Irlanda. En el caso de las Islas Canarias, los estudios se centran en las costas oeste de la isla de La Palma y el Hierro, donde se especula que pueda haber yacimientos de gas y petróleo o reservas minerales de hierro, cobalto y níquel ${ }^{26}$.

\section{LAS PECULIARIDADES DE LA DELIMITACIÓN DE LOS ESPACIOS MARÍTIMOS DE LAS ISLAS Y ARCHIPIÉLAGOS. LAS SINGULARIDADES DE CANARIAS}

III.1. El espacio marítimo interinsular de los Estados Archipielágicos y de los Archipiélagos de Estado.

El Convenio de 1982 establece una serie de espacios marítimos especiales entre los que se encuentran, por sus específicas circunstancias geográficas, las islas y archipiélagos. Las islas, individualmente consideradas, tienen derecho a los mismos espacios marítimos que la tierra firme continental (art. 121.2) aunque se ex-

${ }^{25}$ La Ley 41/2010, de 30 de diciembre, de protección del medio marino ya prevé que la Ley resulta de aplicación al mar territorial, a la ZEE y a la plataforma continental «incluida la plataforma continental ampliada que España pueda obtener en aplicación del procedimiento previsto en el art. 76 de la Convención de Naciones Unidas sobre el Derecho del Mar».

${ }^{26} \mathrm{El}$ argumento de España es que hasta unas 350 millas al oeste de El Hierro el suelo marítimo tiene el mismo origen volcánico que el Archipiélago y, por tanto, forma parte del mismo complejo geológico por lo que puede considerarse plataforma de las Islas Canarias. Se prevé algún tipo de conflicto con Portugal, puesto que se solapan algunas decenas de kilómetros con las plataformas pretendidas para Madeira y Azores (véase las declaraciones de Eduardo Balguerías, director del Instituto Español de Oceanografía, en información publicada por Diario de Avisos de 31 de diciembre de 2010). 
cluye expresamente de la zona económica exclusiva y de la plataforma continental a «las rocas no aptas para mantener habitación humana o vida económica propia» (art. 121.3).

El asunto que ahora nos ocupa es analizar si los Archipiélagos, por ser un conjunto de Islas relacionadas entre sí por proximidad geográfica y por compartir otros elementos políticos, económicos, geológicos, históricos, etc., deben tener, respecto a sus espacios marítimos interinsulares, algún régimen diferenciador respecto a las islas individualmente consideradas.

A lo largo del siglo XX, como apuntábamos anteriormente, fue creciendo el interés de los Estados con litoral en aumentar su control sobre los espacios marítimos adyacentes. En paralelo, a lo largo de ese siglo, con la progresiva descolonización, fueron apareciendo nuevos Estados, algunos de ellos con territorio exclusivamente insular.

Filipinas fue pionera en demandar un régimen jurídico específico para las aguas que separan o que unen (según se quiera ver) las distintas islas del archipiélago. Esta pretensión, declarada unilateralmente por muchos de estos nuevos Estados Archipielágicos ${ }^{27}$, no logró reconocimiento internacional hasta el Convenio de Montego Bay de 1982. Fue una de las concesiones de las grandes potencias mundiales (EE.UU. y la URSS), aliados en este punto a los países con flotas importantes (como Reino Unido o Japón), reticentes a que este reconocimiento implicase obstáculos a la libre navegación, pero que se limitó a los Estados Archipiélagicos, es decir, a aquellos Estados exclusivamente formados por islas, sin territorio continental, dejando fuera a los Archipiélagos que forman parte de un Estado mixto, esto es, formado por territorio continental y archipiélagos. O dicho de otra forma, no concede este régimen específico de delimitación de los espacios marítimos a aquellos archipiélagos que no son soberanos o independientes. Esto implica un tratamiento discriminatorio para los Archipiélagos de Estado, como es el caso de las Islas Canarias, sin que sea fácilmente justificable, la única razón es su status político de ser o no soberano.

El Convenio, en sus artículos 46 a 54, reconoce que los Estados Archipielágicos, formados exclusivamente por islas, podrían trazar sus líneas de base (desde las que luego partir para calcular las franjas de mar territorial y otras) no des-

${ }^{27}$ Díez de Velasco $(2009,510)$ relaciona, al menos, a: Antigua y Barbuda, Bahamas, Cabo Verde, Comores, Fiji, Filipinas, Indonesia, Islas Marshall, Islas Salomón, Jamaica, Kiribati, Maldivas, Papúa-Nueva Guinea, San Vicente y Granadinas, Santo Tomé y Príncipe, Seychelles, Tonga, Trinidad y Tobago, Tuvalu y Vanuatu. Véase, en la misma obra (154 y ss.) lo relativo a la teoría general sobre el acto unilateral del Estado y su importancia en la formación de la costumbre como fuente básica del Derecho Internacional. 
de los puntos de la bajamar de su costa (que es el sistema general de líneas de base), sino desde líneas de base rectas que unieran los puntos más salientes de las diferentes islas del archipiélago; líneas que formarían un polígono en el que quedarían incluidas las islas y mar interinsular ${ }^{28}$. Las aguas así delimitadas estarán sometidas a un régimen especial, previsto en los arts.49 y 50 del Convenio, que reconoce la soberanía del Estado archipielágico sobre ellas (incluido el lecho marino, el subsuelo, todos los recursos que hubiera, y el espacio aéreo), pero con ciertas limitaciones para salvaguardar la navegación, similares a las establecidas sobre el mar territorial ${ }^{29}$.

En el gráfico que se incluye a continuación puede verse el polígono de líneas de base rectas archipielágicas aplicado al caso de Canarias; es a partir de esas líneas desde donde se empezaría a contar para luego determinar el mar territorial, la zona contigua, etc. Realmente, respecto a posibles ventajas económicas de esta fórmula, hay que tener en cuenta que la ZEE no aumentaría sensiblemente, en tanto que, con el actual sistema, al poder contar las 200 millas desde cada una de las Islas y en todas direcciones, se solaparían las áreas de unas Islas con otras. La principal ventaja para el Archipiélago, como se analizará en las siguientes páginas, sería de tipo jurídico, al evitar la existencia de aguas internacionales entre las Islas, (actualmente las hay entre todas ellas, salvo entre La Gomera y Tenerife y entre Fuerteventura y Lanzarote donde, al no haber más de 24 millas entre ellas, toda la distancia es de mar territorial o aguas interiores, como podía observarse en el gráfico anterior).

${ }^{28}$ El trazado de este polígono debe tener una serie de requisitos: 1 . Dentro de ese trazado deben quedar incluidas las islas principales y un área en la que la relación entre la superficie marítima y la superficie terrestre, incluidos los atolones, sea entre 1 a 1 y 9 a 1. 2. La longitud de tales líneas de base no excederá de 100 millas marinas (no obstante, hasta un 3\% de esas líneas podrá exceder hasta un máximo de 125 millas). 3. El trazado de tales líneas de base no se desviará apreciablemente de la configuración general del archipiélago. 4. Las líneas no se trazarán desde puntos que emerjan en bajamar. 5. No podrán utilizar este sistema si se aisla de la alta mar o de la ZEE el mar territorial de otro Estado; véase un análisis detallado de la cuestión en Yturriaga Barberán $(1993,389$ y ss.).

${ }^{29}$ La principal particularidad del régimen jurídico de las aguas archipielágicas radica en los deberes de los buques durante su paso (que incluso pueden desviarse por unas rutas concretas con autorización de la Organización Marítima Internacional), así como en las facultades de reglamentación del ribereño. A juicio de Pulido Bejines $(2009,139)$ se puede considerar «como una especie de híbrido entre el derecho de paso inocente y el derecho de paso en tránsito». Para Díez de Velasco $(2009,513)$ también hay que incluir otras limitaciones que respeten derechos de pesca adquiridos por otros Estados en esas aguas cuando eran consideradas alta mar. 


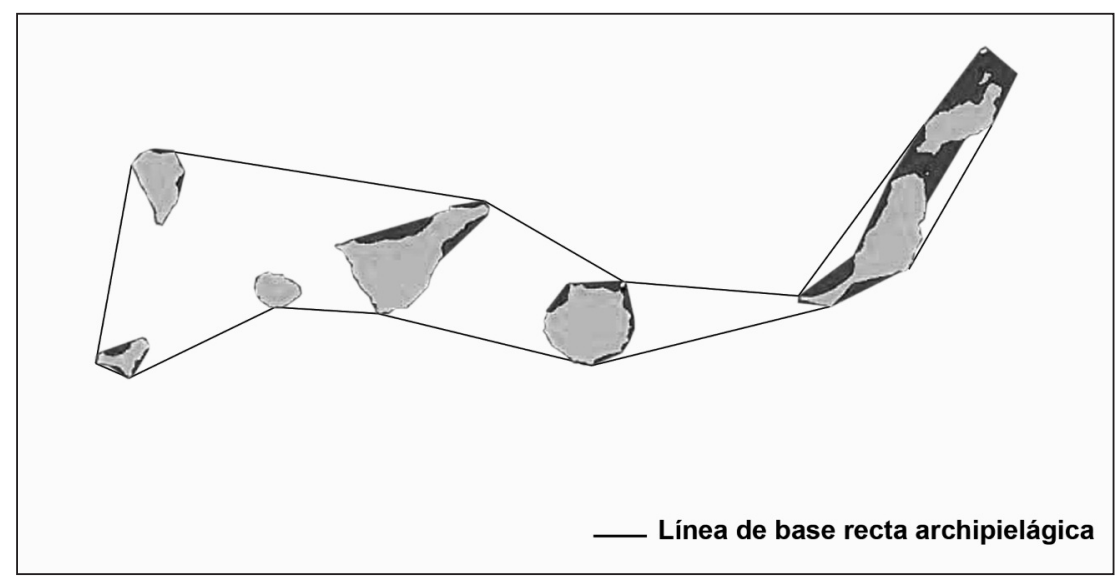

FUENTE: ELABORACIÓN PROPIA.

III.2. La problemática específica de delimitación de los espacios marítimos de las Islas Canarias.

Determinar el régimen jurídico de los espacios marítimos en torno a las Islas Canarias plantea una serie de problemas jurídicos de distinta naturaleza. Por un lado hay que analizar el régimen jurídico nacional previo al Convenio de Montego Bay de 1982, que no es especialmente coherente. Por otra parte, tenemos el mencionado Convenio de Montego Bay, vigente en España desde 1997, que impone fuertes limitaciones a los Archipiélagos de Estado frente a los Estados Archipielágicos, por lo que parte de la doctrina, de la clase política e incluso de los tribunales españoles intentan buscar argumentos y fórmulas para eludirlo o atenuarlo, incluyendo paralelismos con varios ejemplos de derecho comparado. En las siguientes páginas se analizan todos estos puntos de vista para poder comprender los planteamientos que están siendo expuestos en diversas propuestas legislativas.

Anteriormente, al determinar el concepto de aguas interiores, mencionamos que nuestro país, mediante la Ley 10/1977 estableció la delimitación de las líneas de base de las costas atlánticas, incluidas las Islas Canarias, sobre las que luego aplicar las doce millas de mar territorial. Como puede comprobarse sobre un mapa, entre Tenerife y La Gomera, separadas por una distancia inferior a $24 \mathrm{mi}-$ llas, se superponen las doce millas contadas desde cada isla y ambas quedan in- 
corporadas dentro de un conjunto o perímetro. El caso de Fuerteventura y Lanzarote y sus respectivos islotes (Lobos de la primera y La Graciosa y otras de la segunda) es algo diferente puesto que este conjunto quedó encuadrado dentro de un polígono de líneas de base rectas, según prevé el Decreto 2.510/1977, desde el cual debe comenzar a medirse las doce millas del mar territorial. Sin embargo, puede verse que en los restantes casos, donde la distancia entre unas y otras Islas es de más de 24 millas, hay zonas fuera del mar territorial. No prevé, pues, esa norma que se aplicase el criterio de líneas de base recta entre las diferentes Islas, tal y como unilateralmente venían haciendo diversos Estados Archipielágicos (y también algunos Estados mixtos como Ecuador con Islas Galápagos o Dinamarca con Islas Feroe, y que veremos en el siguiente epígrafe) y que luego admitiría el Convenio de Montego Bay de 1982, aunque sólo para los Archipiélagos de Estado.

Sin embargo, la Ley 15/1978 sobre delimitación de la Zona Económica, sin guardar coherencia con la Ley de 1977 antes señalada, establece que, para calcular la ZEE de las 200 millas (adelantándose a lo que en ese momento se debatía en los trabajos de preparación del Convenio de 1982), en el caso de las Islas Canarias se calcularía a partir de las líneas de base recta perimetrales establecidas entre las Islas del Archipiélago ${ }^{30}$, y no a partir de las líneas de base alrededor de cada una de las Islas (que hubiese sido lo procedente según la Ley 10/1977 y el Decreto 2.510/1977), es decir, aplicaría el criterio que unos años después el Convenio de Montego Bay autorizaría a los Estados Archipielágicos.

La Ley de 1978 no prevé la derogación expresa de la Ley de 1977 respecto a la forma de establecer las líneas de base en las Islas Canarias, pero, parece evidente que hay una incongruencia entre ambas normas. No obstante, a nuestro juicio, sería arriesgado sostener la derogación tácita parcial (sólo en lo referido a la delimitación de los espacios marítimos de Canarias) de la Ley de 1977 aplicando el criterio cronológico (por el que prevalecería la Ley posterior, la de 1978), ya que no podemos dejar de advertir que no hay una clara identidad en el objeto de la norma (la Ley de 1978 sólo se refiere al punto de partida sobre el que calcular la ZEE, desde la línea de base recta archipielágica, y la de 1977 fija el criterio de la línea de base normal para delimitar el mar territorial) ${ }^{31}$. Hay que

\footnotetext{
${ }^{30}$ Debe hacerse constar que el Gobierno español no llegó a aprobar los Decretos de desarrollo de la Ley de 1978 especificando el trazado de esas líneas de base rectas.

${ }^{31}$ A favor de considerar derogada, en el punto que nos ocupa, la Ley de 1977 por la Ley de 1978 se manifiesta Torres Lana $(2009,520)$ «la incompatibilidad de ambas normas es manifiesta». En el mismo sentido, con algo más de cautela, el Tribunal Supremo (STS de 18 de junio de 1992 F J Quinto, reiterada en la más reciente de 16 de junio de 2008 F J Séptimo) «cabe suponer derogada tácitamente la Ley 10/1977, por la posterior de 20 de febrero de 1978».
} 
añadir, por otra parte, que en 1978 la Zona Económica Exclusiva aún carecía de regulación internacional (será la Convención de 1982 la que lo haga). Sin embargo, la Ley de 1978 se entendía como una apuesta decidida de España por reivindicar tanto las 200 millas de ZEE como el criterio de línea de base recta archipielágica para delimitar los espacios marítimos de sus Archipiélagos, tal y como estaba defendiendo en los trabajos preparatorios de la Convención de 1982.

Finalmente, como sabemos, el Convenio de 1982 establece un régimen general de delimitación de los espacios marítimos adyacentes a tierra firme por medio de líneas de base aplicable a Estados ribereños (art. 5) y también a islas y archipiélagos (art. 121); y establece un régimen especial (arts. 46 y ss.) para Estados Archipiélagos ${ }^{32}$. Ciertamente, no se establece una mención expresa que prohíba aplicar el criterio de líneas de base rectas archipielágica a los Archipiélagos de Estado, pero debemos aplicar los criterios básicos de interpretación de las normas (art. 3.1 Código civil). Así, teniendo en cuenta el sentido literal y el contexto, los antecedentes históricos y legislativos y el principio de especialidad (se entiende que ante dos preceptos contradictorios donde no podemos aplicar ni el principio jerárquico ni el cronológico, debemos acudir al principio de norma general y norma específica, entendiendo por general el criterio de línea de base y el específico el aplicable sólo a los Archipiélagos de Estado) nos lleva a concluir que, pese a considerarlo un criterio discriminatorio e injustificado, los Archipiélagos de Estado no pueden utilizar el sistema de líneas de base rectas archipielágicas según el Convenio de 1982.

Ruiloba García $(2009$, 480) reconoce que sería pretender «una forzada ampliación del ámbito de aplicación del régimen convencional previsto para los Estados archipielágicos». Como alternativa, este autor propone que, para acabar con la discriminación injusta entre Estados Archipiélagos y Archipiélagos de Estado,

${ }^{32}$ Yturriaga Barberán (1993, 409 y ss.) relata cómo en los trabajos preparatorios del Convenio de 1982 se establecía que se aplicaría el mismo régimen a todos los archipiélagos, sin tener en cuenta su status jurídico-político, pero, finalmente, por razones estrictamente políticas, se limitó a los Estados Archipielágicos, pese a las protestas de países como Ecuador, España, India o Grecia. Las críticas a esta solución en la doctrina española, como era de esperar, han sido unánimes; véase por todos (por ser el más reciente) a Ruiloba García (2009) que también cita, en la misma línea, a otros autores extranjeros (véase nota al pie $\mathrm{n}^{\circ} 12$ ) y añade «de los Documentos Oficiales de la III Conferencia se desprende que la mayoría de los participantes aceptaron limitar el ámbito de aplicación del principio archipielágico previsto en la Convención a los Estados archipielágicos, excluyendo a los demás archipiélagos». También conviene hacer constar que este Convenio, vigente en España desde 1997, establece expresamente que los Estados firmantes no podrán establecer reservas a la aplicación de ninguno de sus preceptos. 
se podría conseguir el mismo objetivo con la aplicación generosa de los establecido en el art. 7 del Convenio de 1982 que permite la utilización de las líneas de base rectas entre islas con tal de que el trazado que se haga no se aparte «de una manera apreciable de la dirección general de la costa, y las zonas de mar situadas del lado de tierra de esas líneas han de estar suficientemente vinculadas al dominio terrestre para estar sometidas al régimen de aguas interiores» (2009, 496). A nuestro juicio, el art. 7 del Convenio prevé que se utilice el sistema de líneas de base rectas (que una los puntos apropiados y que incluye a las islas y parte del mar adyacente) sólo para las costas junto a las que haya una franja de islas con una proximidad inmediata (como se ha realizado en España con el Decreto 2.510/1977 con el conjunto de las islas de Lanzarote y Fuerteventura con sus respectivos islotes, todos ellos muy próximos). Sin embargo, sostener que este sistema se pudiera aplicar también a archipiélagos oceánicos (con islas a más de 24 millas unas de otras) sería caer en el absurdo de hacer innecesaria la previsión de los arts. 46 y ss. del Convenio de Montego Bay que establece un régimen específico de delimitación para los Estados Archipielágicos, e, incluso, sería dar a esas aguas el status de aguas interiores, más ventajoso que el de aguas archipielágicas; por ello nos parece que no resulta razonable. En contra de lo que aquí se señala, hay que mencionar que este ha sido el sistema utilizado por Portugal en 1985 para, parcialmente, trazar varias líneas de base rectas entre diversas Islas de los Archipiélagos de Madeira y de Azores.

Pese a lo anterior, algún autor sí entiende que el sistema de líneas de base archipielágicas es aplicable para Canarias, así, Torres Lana $(2009,525)$ que apela a que «el precepto no contempla — pero tampoco prohíbe- el trazado de esas líneas de base para los Estados mixtos». Por otra parte, esta doctrina también se ha encontrado con el apoyo de la STS de 18 de junio de 1992 y, en sobre todo, de la STS de 16 de junio de 2008, que analizaremos a continuación ${ }^{33}$.

La primera de esas sentencias trata la obligación de la compañía marítima Transmediterránea de abonar un impuesto autonómico sobre carburantes cuando efectúa trayectos interinsulares cuando, según se argumenta, se realizan parcialmente por aguas internacionales. La sentencia acabará desestimando la pretensión de la compañía naviera, en primer lugar por descartar que este supuesto

${ }^{33}$ De hecho, esta sentencia ha sido utilizada como argumento jurídico fundamental por el representante del PSOE, Segura Clavell, para votar a favor de la toma en consideración de la proposición de ley de CC en diciembre de 2009 antes mencionada (véase Diario de Sesiones del Congreso de los Diputados $n^{\circ} 131$ de 15 de diciembre): «Esta es una doctrina que el Tribunal Supremo recomienda al Gobierno aprovechando para pronunciarse en la legitimación del Gobierno del Estado para trazar líneas archipielágicas». 
se trate de una operación de navegación marítima internacional, es decir, que parta del ámbito territorial de aplicación del impuesto pero que concluya fuera del mismo o viceversa, dado que el trayecto parte de una isla y acaba en otra. Pero, en segundo lugar, en lo que aquí interesa, también señala en su $\mathrm{F} \mathrm{J} 5^{\circ}$ que «cabe suponer derogada tácitamente la Ley 10/1977 por la posterior de 20 de febrero de 1978, interpretando al mismo tiempo el art. 2 del Estatuto de Autonomía de Canarias (Ley Orgánica 10/1982, de 10 de agosto), como expresión de un todo unitario descrito por la relación de sus componentes, dentro de un espacio comprensivo de suelo, subsuelo, espacio aéreo y las aguas territoriales que circundan el perímetro archipielágico e incluyen los espacios interinsulares de aguas encerradas». Es decir, parece que el Tribunal Supremo entiende que en Canarias hay una unidad jurídica entre las Islas y sus aguas interinsulares.

Dejando al margen la posible derogación de la norma de 1977, hay que tener en cuenta otras dos cuestiones: a) Una es que en 1992 la Convención de Montego Bay no ha entrado aún en vigor para España, por lo que la Ley de 1978 sobre la delimitación de la ZEE desde el polígono de líneas de base recta archipielágica está vigente en nuestro país (aunque sin desarrollo reglamentario), si bien, lo cierto es que el hecho imponible del impuesto discutido no tiene relación directa con la ZEE; y b) Que resulta algo artificioso que el Tribunal Supremo deduzca ese conjunto unitario de Islas y perímetro arhipielágico marítimo y aéreo del precepto estatutario de $1982^{34}$.

La STS de 16 de junio de 2008 analiza el recurso de la Administración General del Estado contra la SAN que daba la razón a la Compañía Telefónica al eximirla de una parte del canon que se le exigía por la ocupación de espacio con un cable de comunicaciones submarino entre las Islas de Gran Canaria y Tenerife. La Compañía acepta abonar el canon por la ocupación de los metros situados en la zona marítimo terrestre y el mar territorial, que considera de dominio público estatal; pero entiende que sobre la ZEE y plataforma continental el Estado no tiene ese dominio público por lo que, si bien debe prestar su consentimiento, sólo tiene poder sobre sus recursos económicos, por lo que si quiere cobrar un canon sobre los metros situados en esas zonas deberá acreditar que el cable afecta a esos recursos. El Tribunal Supremo confirmará la SAN, pero lo que aquí interesa es otra cuestión. El TS, pese a que las partes no lo argumentan, decide entrar

${ }^{34}$ El inicial Estatuto de Autonomía de Canarias de 1982, hasta su reforma en 1996, decía en su art. 2: «Canarias comprende los territorios insulares integrados por las siete islas de El Hierro, Fuerteventura, Gran Canaria, La Gomera, Lanzarote, La Palma y Tenerife, así como por las islas de Alegranza, La Graciosa, Lobos y Montaña Clara, Roque del Este y Roque del Oeste, agregadas administrativamente a Lanzarote, salvo la de Lobos, que lo está a Fuerteventura». 
de lleno a analizar el status jurídico de las aguas interinsulares (recordamos que entre Tenerife y Gran Canaria hay más de 24 millas, por lo que hay una zona que supera el mar territorial - 12 millas - calculado desde la costa de cada una de las dos Islas). Insiste nuevamente en que en la delimitación de los espacios marítimos de Canarias se debe aplicar el principio archipielágico de líneas de base rectas, por así preverlo la Ley de 1978 que habría derogado tácitamente la Ley de 1977, como ya hizo en la STS de 1992, y reprocha al Gobierno del Estado que no las haya trazado. Pero la STS de 2008 da un paso más y en su FJ $8^{\circ}$, que lo podemos considerar como obiter dicta de la sentencia, señala que «podemos añadir diversos argumentos que avalarían la «tácita derogación» de la norma de 1977» y enumera los siguientes:

- Contradicción entre la norma de 1978 y la de 1977 respecto a la delimitación de las líneas de base en Canarias.

- Concepto de Archipiélago, que incluye algo más que el territorio de las Islas que lo componen, fundamentándose en la nueva redacción del art. 2 del EACan dado en la reforma de $1996^{35}$ y añadiendo, como argumento de lege ferenda, el texto de la reforma frustrada del EACan de $2006^{36}$.

- La condición del Archipiélago como Región Ultraperiférica de la Unión Europea y su equiparación con otras RUP como Madeira y Azores que ya han adoptado el principio archipielágico en la delimitación de sus espacios.

- No habría contradicción entre la Ley española de 1978 y lo establecido en la Convención de Montego Bay ante la ausencia de una expresa prohibición en el texto internacional ya que, en todo caso, no se «prejuzga el estatuto de las aguas archipielágicas o interiores ni el régimen de nave-

${ }^{35}$ El art. 2 del EACan según su reforma de 1996 dice: «El ámbito territorial de la Comunidad Autónoma comprende el Archipiélago Canario integrado por las siete Islas de El Hierro, Fuerteventura, ...».

${ }^{36}$ El art. 1 decía: «Canarias es un archipiélago atlántico que, como expresión de su identidad singular basada en sus circunstancias geográficas, históricas y culturales (...)». El art. 3.1: «El ámbito territorial de la Comunidad Autónoma de Canarias comprende el archipiélago canario, integrado por las siete islas de El Hierro, Fuerteventura, (...), por el mar que las conecta y por el espacio aéreo correspondiente». El art. 3.2: «Las aguas interinsulares se definen a partir del perímetro del Archipiélago, delimitado de acuerdo con el polígono de líneas de base rectas que unan los puntos extremos de las islas». El art. 3.3: «La Comunidad Autónoma de Canarias ejercerá sus competencias en el ámbito espacial del archipiélago canario, definido en el apartado 1 anterior, en el mar territorial, en la zona económica exclusiva, en el lecho y subsuelo de estos espacios marítimos y en su espacio aéreo» (Proposición de ley de reforma del Estatuto de Autonomía de Canarias presentada por el Parlamento de Canarias, Boletín Oficial de las Cortes Generales de 22 de septiembre de 2006). 
gación a través de las mismas, permaneciendo inalterables a tal efecto las normas y usos internacionales, como sería el denominado paso inocente a través de los estrechos o rutas marítimas establecidas».

- Relaciona los casos, ya mencionados y que luego analizaremos, de derecho comparado donde varios Estados mixtos han establecido el principio archipielágico.

- Alude a la sentencia del Tribunal Internacional de Justicia de 1951 en el asunto de las pesquerías anglonoruegas, donde se reconoció una zona de pesca exclusiva que incluía las aguas encerradas por un sistema de líneas rectas que unían los puntos más salientes de las Islas Skjaergaard.

A nuestro juicio, estos argumentos del Tribunal Supremo se trata más de consideraciones para defender la injusticia de que los Archipiélagos de los Estados mixtos no puedan delimitar los espacios marítimos según el principio archipielágico, como sí pueden los Estados Archipielágicos, que de argumentos que utilicen el derecho positivo vigente en nuestro país.

Algunas de las cuestiones que plantea la STS de 2008 ya han sido tratados anteriormente, pero, por su trascendencia, quizá sea necesario volver sobre la cuestión de la viabilidad de la utilización del principio de línea archipielágica en Canarias. Puede defenderse, con fundamento jurídico (ya lo vimos anteriormente, aunque decíamos que, a nuestro juicio, no había una nítida identidad en el objeto de la norma derogada y derogante) que la Ley de 1978 derogaba la de 1977 en lo concerniente al sistema de delimitación de las líneas de base en torno a Canarias; pero, con más claridad, habría que admitir que la entrada en vigor en España, en 1997, del Convenio de Montego Bay de 1982 implica la derogación sobrevenida de la Ley nacional de 1978, ya que, como vimos anteriormente, aplicando los principios generales de interpretación jurídica sobre los que tenemos consenso, no hay interpretación posible que nos lleve a pensar que el principio de delimitación archipielágica de Montego Bay sea aplicable a los Archipiélagos de Estados mixtos. Otra cosa es que se quiera denunciar una más que probable injusticia y apoyar los intereses nacionales para forzar el ordenamiento jurídico internacional (seguramente menos rígido que los nacionales, y como ya han hecho otros Estados), pero nos parece que eso es más propio de órganos políticos como el Gobierno o las Cortes Generales que de los tribunales de justicia nacionales.

Ciertamente, cabría analizar que si la Ley de 1977 (y su Decreto 2.510/1977 de desarrollo) fue tácitamente y parcialmente derogada por la Ley de 1978 (que establece un sistema de delimitación diferente, aunque nunca concretado en el necesario desarrollo reglamentariamente), y la Ley de 1978 ha sido derogada por la entrada en vigor en España en 1997 del Convenio de Montego Bay (tengamos en cuenta que el Convenio de Montego Bay de 1982 establece cómo deben ac- 
tuar los Estados ribereños en esa delimitación, pero debe haber un acto propio de cada Estado haciéndolo), ¿cuál es realmente la norma española que actualmente delimita los espacios marítimos en torno a Canarias?, ¿es posible que la norma de 1977 vuelva a tener vigencia sin una decisión del legislador?, ¿carecemos actualmente de norma vigente?, ¿es, por tanto, imprescindible una iniciativa legislativa que delimite las líneas de base para luego determinar los espacios marítimos en Canarias?, ¿se debería hacer en la misma forma en que se actuó en 1977 o llegados a este punto se debería seguir el camino ya emprendido por otros Estados Mixtos como Portugal? Analizaremos la Ley 44/2010 en las páginas siguientes.

\section{III.3. La Situación de otros Archipiélagos de Estado en Derecho comparado.}

Los partidarios de que se reconozca el derecho de España a utilizar el sistema de líneas de base rectas archipielágicas para Canarias, frente a la principal objeción fundamentada en lo previsto en el Convenio de Montego Bay de 1982 ya analizada en el apartado anterior, suelen argumentar que, pese a ello, existen otros Estados mixtos que sí lo aplican a sus Archipiélagos de Estado desde antes de la aprobación del Convenio de 1982 (Ecuador con las Islas Galápagos ${ }^{37}$, Dinamarca con las Islas Feroe $^{38}$, Noruega con el Archipiélago Spitzberg ${ }^{39}$ - o Svalvard—). También hay otros Estados que lo hacen después de 1982, como Australia con las Islas Houtman (mediante Proclama de 4 de febrero de 1983), o Portugal ${ }^{40}$ con las Islas Azores y Madeira (mediante Decreto Ley de 29 de noviembre de $1985^{41}$ ). Los casos de India respecto de sus archipiélagos de Andaman, Nicobar y las Islas Laquedivas; Canadá

${ }^{37}$ Ecuador fue el primer Estado mixto que aplicó el sistema de líneas de base rectas al archipiélago de Colón o Galápagos en 1951, mediante Decreto del Congreso de 21 de febrero, luego respaldado por la Declaración de Santiago de 1952 y por la reforma del art. 633 de su Código civil en 1966.

${ }^{38}$ Dinamarca estableció el mismo sistema en torno a las Islas Feroe en 1963 y en 1976 proclamó la zona exclusiva de pesca de 200 millas a partir del perímetro archipielágico (Orden no 599 de 21 de diciembre).

${ }^{39}$ Noruega hizo lo propio en 1970 sobre el Archipiélago Spitzberg mediante Real Decreto de 25 de septiembre.

${ }^{40}$ Téngase en cuenta que Portugal hizo una reserva a la Convención de 1982 respecto a la delimitación de sus espacios marítimos y que afectaría a Madeira y Azores; sin embargo, dado que esta posibilidad está expresamente prohibida por la propia Convención, debe considerarse nula.

${ }^{41}$ También hay que especificar que Portugal no unió en Madeira todas las islas con la línea de base recta archipielágica (sólo lo hizo entre las Islas Desertas y Madeira, no con Porto Santo, probablemente con la intención de que las Desertas, que carecen de población, pudiesen tener ZEE), 
en relación con su archipiélago ártico o Sudáfrica con las Islas Penguin se mueven en una mayor ambigüedad ${ }^{42}$.

Para la doctrina internacionalista, se trata de actos unilaterales ${ }^{43}$ que no son oponibles frente a terceros Estados salvo aprobación expresa o, cuando menos tácita $^{44}$, de los afectados. Desde la perspectiva más favorable a los intereses de estos Estados mixtos, se podría contemplar la posibilidad de que se esté formando una «costumbre» que, en Derecho Internacional, es una esencial fuente del Derecho. Adviértase, como se vio anteriormente, que numerosos Estados Archipielágicos adoptaron unilateralmente el criterio de las líneas de base recta archipielágica que más tarde fue reconocido en la Convención de Montego Bay de 1982.

En los casos mencionados, no ha habido protestas masivas ni reiteradas de otros Estados, probablemente debido a cuestiones geográficas, ya que se trata de Archipiélagos alejados de otros Estados y fuera de las rutas marítimas frecuentes.

\section{4. Los problemas de delimitación de otros espacios marítimos en torno a las islas} canarias:

A continuación veremos los problemas que se plantean, de forma específica, para el Archipiélago canario. Para el análisis de las problemas específicos en relación con Baleares, véase Orihuela (1985, 350 y ss.).

\section{a) La delimitación con Marruecos.}

Tanto España como Marruecos se adelantaron unilateralmente, con sus legislaciones internas, a establecer una ZEE antes de que ésta fuese aprobada por el Convenio de 1982. España lo hace con la Ley 15/1978, de 20 de febrero y la establece en 200 millas de anchura y Marruecos hace lo propio con el Dahir ${ }^{\circ} 1-81$ 178 de 1981.

sino que recurrió a un uso más que excesivo de delimitación de aguas interiores. En el caso de Azores el método fue similar y tampoco unió todas las islas, sino que lo hizo en tres grupos uniendo las más occidentales, las centrales y las orientales.

${ }^{42}$ Véase Ruiloba García (2009, 485).

${ }^{43}$ Véase Díez de Velasco (2009, 149 y ss.) o González Campos y otros (2008, 178 y ss.).

${ }^{44}$ Varios autores han destacado el papel de «gendarme mundial» que en estos aspectos, y en otros muchos, desempeña EE.UU. como superpotencia y contraria a nuevos y extensivos límites de la alta mar y a la zona ZIFMO (Zona Internacional de los Fondos Marinos y Oceánicos), y que ha presentado diversas notas de protesta oficiales ante la Oficina Marítima Internacional contra esos actos unilaterales (Lacleta Muñoz, 2005, 9, o Ruiloba García, 1999, nota al pie 20). 
Anteriormente señalábamos que, para la delimitación de la ZEE y de la plataforma continental entre Estados vecinos, preferentemente se debía llegar a una solución equitativa según los criterios del Derecho Internacional, entre los que se encontraban diversos factores (geográficos, socioeconómicos, etc.), y subsidiariamente se debía acudir a la regla de la equidistancia ${ }^{45}$. Como recuerda Orihuela $(1985,338)$ ninguno de los Convenios del Mar, incluido el vigente, «establece una norma específica aplicable a la delimitación de espacios marinos entre Estados adyacentes y opuestos cuando entran en juego las islas» ${ }^{46}$.

Aquí tenemos el origen de uno de los contenciosos con Marruecos en torno a las Islas Canarias. España aún no ha llegado a ningún acuerdo con Marruecos para poder fijar la mediana de la ZEE por varios motivos ${ }^{47}$, uno de ellos es porque el Reino Alauita pretende que el factor insular del territorio español implicado, muy lejano al Estado continental al que pertenece, frente a sus costas atlánticas justificaría que se ampliase la zona marroquí, más allá de la equidistancia, en detrimento de la que correspondería a Canarias, y también porque alega que la plataforma continental marroquí es más amplia que la de las Canarias ${ }^{48}$. Por su parte, España alega otras circunstancias relevantes según el derecho internacional que también deben tenerse en cuenta como corrección de la equidistancia a favor de España: la alta dependencia de Canarias de la riqueza de las aguas marítimas, alta densidad de población de las Islas, etc.

En cualquier caso, hay que señalar que, por la vía de los hechos, tanto Marruecos como España están dando por válida la equidistancia; así se comprueba con el Decreto 1.462/2001, de 21 de diciembre (BOE n 20 de 23 de enero de 2002) por el que el Gobierno español ha otorgado permisos de investigación de

${ }^{45}$ La Ley española de 1978 alude a la equidistancia «salvo lo que se disponga en tratados internacionales»y, en cambio, el Dahir marroquí de 1981 sólo acude a la equidistancia «sin perjuicio de las circunstancias geográficas o geomorfológicos» y teniendo en cuenta todos los factores pertinentes según derecho internacional.

${ }^{46}$ Para un análisis detallado de la delimitación de los espacios marítimos cuando están involucradas las islas, véase Gómez-Robledo Verduzco (1998).

${ }^{47}$ Otros motivos son: problemas de delimitación en otras zonas de las costas vecinas mediterráneas (Ceuta, Melilla y otros), véase Lacleta (2003); el problema de la discutida soberanía del Sáhara Occidental (que afectaría a todo acuerdo al sur del paralelo $27^{\prime} 40^{\circ}$ ) y que se encuentra enquistado desde la salida de España en 1975; y otros como, a juicio de España, la excesiva amplitud de una línea de base recta en la costa marroquí entre Cabo Ohir y Cabo Jubi, frente a las costas Canarias.

${ }^{48}$ Orihuela $(1985,356)$ recuerda que el Tribunal Internacional de Justicia, en el caso que enfrentó a Libia y Malta en 1985, ya estableció que este elemento era irrelevante en los casos de Estados situados frente a frente a menos de 400 millas. 
hidrocarburos ${ }^{49}$ a la empresa REPSOL ${ }^{50}$ en el subsuelo marino frente a las costas de las islas de Fuerteventura y Lanzarote y más acá de la mediana con Marruecos, lo que ha provocado la protesta marroquís ${ }^{1}$. Pese a ello, Marruecos también ha hecho lo propio, desde la década de los 90, con otras empresas petrolíferas norteamericanas y francesas como Kerr-McGee y Total Fina Elf ${ }^{52}$.

\section{b) La delimitación con las Islas portuguesas.}

La delimitación entre Canarias y Madeira podría ser sencilla, al tratarse en ambos casos de Archipiélagos, y, en consecuencia, podría ser la simple utilización del criterio de la equidistancia. Sin embargo, España y Portugal mantienen discrepancias en torno a la delimitación de los espacios por el diferente peso que uno y otro quieren dar a las Islas Salvajes ${ }^{53}$, entre Madeira y Canarias, deshabitadas a excepción de cierta presencia militar.

Ya vimos anteriormente que el Convenio de 1982 excluía de derecho a ZEE y plataforma continental a las rocas sin vida humana y económica propia. Orihuela $(1985,340)$ analiza esta cuestión y concluye que se exige la presencia de

${ }^{49}$ En todo caso, Martín Ruiz $(2005,17)$ recuerda que «la naturaleza y estructura volcánicas de las islas hacen que la posibilidad de existencia de yacimientos de hidrocarburos en su plataforma insular sea muy improbable, y de existir tendría relación con la estructura geológica de la plataforma continental africana», aunque añade que nuevos estudios recientes no lo descartan.

${ }^{50}$ El diario La Opinión del 20 de noviembre de 2009, p.23, informaba de la controversia entre el Gobierno de España y REPSOL en tanto que el primero considera que la compañía petrolífera no ha pedido la prórroga de los permisos y ha abandonado definitivamente el proyecto y la segunda, por su parte, considera que los permisos aún están vigentes y sólo hace falta que el Gobierno retire la paralización que dio a los estudios en 2005 ante la falta de consenso entre las fuerzas políticas canarias sobre la conveniencia de seguir con el proyecto ante una posible incidencia medioambiental que afectara al turismo de las islas.

${ }^{51} \mathrm{Ha}$ sido considerado por el Gobierno marroquí como acto unilateral, discutible, hostil e inaceptable, enviando un comunicado de protesta el 31 de enero de 2002 a la Embajada española en Rabat.

${ }^{52}$ Martín Ruiz $(2005,9)$ recuerda que también ha autorizado al holding formado por las empresas norteamericanas y británicas Lone Star Energy, Anschutz, con la Marocco Corporation y la Enterprise Oil Exploration Limited, también con REPSOL, para que perforen a unas 50 millas al noreste de Lanzarote y Fuerteventura.

${ }^{53}$ Portugal considera que estas Islas son susceptibles de poseer zona económica exclusiva, por lo que, unilateralmente, la ha delimitado, en virtud del Decreto-Ley 119/78; motivo por el que España presentó la correspondiente nota de protesta; en este sentido véase la respuesta del Subsecretario de AA.EE. a la pregunta del senador Barbuzano (Diario de Sesiones del Senado de 3 de diciembre de 1991). 
una población permanente y autónoma sobre las mismas, sin que deba aceptarse, a estos efectos, que haya una población mínima transportada temporalmente desde el continente u otras islas mayores como es el caso de los fareros o destacamentos militares renovados temporalmente ${ }^{54}$.

\section{III.5. Propuestas recientes en torno a los problemas de delimitación de los espacios} marítimos de Canarias. la Ley 44/2010.

La reciente Ley 44/2010, de Aguas Canarias, utiliza una terminología ciertamente ambigua. El párrafo primero de su artículo único establece:

«Entre los puntos extremos más salientes de las islas e islotes que integran, según el artículo 2 de su Estatuto de Autonomía, el Archipiélago canario, se trazará un contorno perimetral que siga la configuración general del archipiélago, tal como se establece en el Anexo de esta Ley. Las aguas que queden integradas dentro de este contorno perimetral recibirán la denominación de aguas canarias y constituyen el especial ámbito marítimo de la Comunidad Autónoma Canaria».

Podemos comprobar cómo en la segunda frase, también en el propio título de la Ley ${ }^{55}$, se especifica que se trata de la delimitación de las «aguas» y elude referirse a la delimitación de los «espacios marítimos», que sería lo más preciso por incluir a los elementos de lecho marino y subsuelo. Por otra parte, tampoco utiliza las denominaciones precisas admitidas por el Derecho Internacional tales como mar territorial, aguas interiores o aguas archipielágicas. Finamente, señala que esas aguas constituyen el «especial ámbito marítimo de la Comunidad Autónoma de Canarias», ¿qué debemos entender por especial?, ¿qué régimen jurídico peculiar tienen esas aguas?

Por otra parte, la disposición adicional única titulada «Respeto al Derecho Internacional» prevé:

«El trazado del contorno perimetral no alterará la delimitación de los espacios marítimos de las Islas Canarias tal y como están establecidos por el ordenamiento jurídico español en virtud del Derecho Internacional vigente».

\footnotetext{
${ }^{54}$ Respecto a los problemas entre España y Marruecos en torno a un problema similar en el Mediterráneo con las Islas Chafarinas véase Lacleta Muñoz (2003).

${ }^{55}$ El título de la Ley 44/2010 «de aguas canarias» nos parece poco afortunado por no ser suficientemente descriptivo. Téngase en cuenta que existe una Ley 29/1985 y otra Ley 12/1990, de aguas, cuyo contenido nada tiene que ver con la que aquí nos interesa por tratar las aguas terrestres superficiales y subterráneas.
} 
Vemos cómo ahora, en esta disposición adicional, sí se habla ya, con más rigor terminológico, de espacios marítimos y no de aguas, pero es precisamente para especificar que la Ley no pretende alterar la delimitación establecida por la normativa vigente aplicable, es decir, actualmente por lo que se señala en el Convenio de Montego Bay de 1982. En consecuencia, no se acierta a comprender qué objetivo real pretende la nueva Ley puesto que en nada altera el régimen jurídico de los distintos espacios marítimos en torno a Canarias que ya había antes de la Ley de $2010^{56}$. No observamos ningún cambio respecto a la situación precedente a excepción de que España, a efectos formales internos, ha decidido denominar a las aguas interinsulares de Canarias como «aguas canarias». De la redacción de la disposición adicional única se deduce que España, al menos por el momento y mediante esta ley, no tiene intención de pretender aplicar el criterio de línea de base recta archipielágica a Canarias y buscar su reconocimiento y respeto frente a la comunidad internacional, que sería lo que sí implicaría un cambio de régimen jurídico para esos espacios.

Otra cuestión sería plantear si, a efectos únicamente internos nacionales, la nueva Ley 44/2010 de Aguas de Canarias supondría un aumento del tamaño espacial de la Comunidad Autónoma. Si se toman en cuenta las nuevas «aguas canarias», el Archipiélago multiplicaría por siete su tamaño, lo que le podría beneficiar enormemente en el reparto de fondos frente a otras Comunidades Autónomas ${ }^{57}$ dado que uno de los parámetros que se utilizan para la asignación de recursos es el de la superficie. A nuestro juicio, parece muy improbable que la Comunidad Autónoma de Canarias logre que el Consejo de Política Fiscal y Económica acepte que ha experimentado un aumento de su superficie cuando lo cierto es que la nueva Ley de 2010 no ha supuesto un aumento de las aguas interiores, del mar territorial u otros espacios para España (ni, consecuentemente, para Canarias) ni una paralela reducción de las aguas internacionales.

También hay que recordar que el art. 147.2.b) dispone, efectivamente, que los Estatutos de Autonomía habrán de delimitar el territorio de su respectiva Co-

\footnotetext{
${ }^{56}$ La Exposición de Motivos de la Ley indica en su párrafo segundo que «Este es un tema de extraordinaria importancia tanto para Canarias como para el Estado español, que no puede seguir dilatándose sin perjuicio, especialmente, de todos los canarios que tienen derecho a que las aguas estén claramente perfiladas, por razones de muy variado tipo que afectan, sobre todo, a la seguridad, a la protección medioambiental y a los recursos de dichas aguas».

${ }^{57}$ El Consejo de Política Fiscal y Financiera aprobó el 15 de julio de 2009 el Acuerdo 6/2009, para la reforma del sistema de financiación de las Comunidades Autónomas de Régimen Común y Ciudades con Estatuto de Autonomía, cuyos principios fueron trasladados a la Ley Orgánica 3/2009, de 18 de diciembre; para un análisis del nuevo modelo véase López Laborda (2010, 151 y ss.).
} 
munidad, por lo que establece así una reserva estatutaria (véase también la STC 99/1986 en relación al caso del Condado de Treviño). No obstante, recordando las ideas expuestas al inicio de este trabajo, resulta indiscutible que la delimitación del territorio nacional, como elemento constitutivo del Estado y oponible frente a otros Estados, es asunto del ente soberano, del sujeto de derecho internacional. Por ello, debemos entender que la Constitución reserva al legislador estatutario la delimitación del territorio autonómico, pero dentro de la delimitación del territorio nacional que previamente haya configurado el propio Estado español ${ }^{58}$ en sus relaciones internacionales, que son de naturaleza exclusiva (art. 149.1.3 ${ }^{\mathrm{a}} \mathrm{CE}$ ). Por otra parte, por la rigidez de la que están dotados los EE.AA en nuestro país, no parece lo más adecuado que un Estatuto de Autonomía, por muy Ley Orgánica estatal que sea, que lo es pero sui generis, sea el tipo de norma por la que el Estado delimite su territorio con efectos en el plano internacional.

El precedente inmediato de la Ley 44/2010, como ya mencionamos, fue la última iniciativa de la proposición de ley del Grupo Mixto (a instancia de Coalición Canaria) sobre delimitación de los espacios marítimos de Canarias que el 15 de diciembre de 2009 fue tomada en consideración por el pleno del Congreso de los Diputados. No obstante, en las dos últimas legislaturas se presentaron diversas proposiciones de ley, en el mismo sentido, a iniciativa de CC, que fueron tomadas en consideración pero decayeron al finalizar las legislaturas. La exposición de motivos de la nueva ley de 2010 recuerda que han sido unas 40 las iniciativas parlamentarias presentadas por este asunto (entre preguntas, mociones, interpelaciones y proposiciones) en los últimos 30 años.

La proposición de 2009 era algo más ambiciosa, aquella iniciativa pretendía que el mar territorial, zona contigua, zona económica exclusiva y plataforma continental se midiesen a partir del perímetro exterior (apartado 3 del artículo único). Además, aquel texto titulaba el artículo único y la propia Ley como «Delimitación de los espacios marítimos de Canarias». Las aguas dentro del perímetro se denominarían «aguas interinsulares» (véase el apartado segundo del artículo único) y tendrían el status jurídico que les correspondiera según «la legislación interna y el Derecho Internacional del Mar» ${ }^{59}$; así, aquella propuesta ya se movía en una ter-

${ }^{58}$ Díez-Picazo (1987, 153), aunque refiriéndose a un asunto territorial distinto (el Condado de Treviño) al que aquí nos ocupa, señala que: «Los entes territoriales infraestatales no tienen, por consiguiente, más derecho sobre su territorio, ni más posibilidad de reivindicar o ceder porciones territoriales, que el que les reconozca el ordenamiento general del Estado».

${ }^{59}$ En esta línea, Torres Lana $(2009,525)$ que defiende que «las aguas resultantes de esta delimitación, llámense archipielágicas, interinsulares o de cualquier otra forma que resulte expresiva de su configuración, no alterarían su estatuto internacional ni afectarían a los derechos de 
minología deliberadamente ambigua con el propósito de intentar no chocar frontalmente con las disposiciones del Convenio de Montego Bay ${ }^{60}$.

Finalmente, la Ley 44/2010, como ya se hacía en la proposición de 2009, ha delimitado el espacio de «aguas canarias» con una ampliación respecto a iniciativas anteriores porque en el Anexo 1 y Anexo 2 se puede comprobar que en el trazado del polígono se ha unido directamente el punto sur de El Hierro con el punto sur de Tenerife (sin pasar por La Gomera) y también el norte de Gran Canaria con el oeste de Lanzarote sin pasar por Fuerteventura. De esta manera se aumenta el área delimitada, lo que, de considerarlo espacio propio de la Comunidad Autónoma de Canarias, supondría multiplicar por siete el actual. Este nuevo trazado en beneficio de los intereses nacionales, si buscase efectos de reconocimiento internacional tendría el inconveniente de alejarse del mandato de que las líneas de base recta deben seguir el trazado natural del contorno del archipiélago; por otra parte, también serían líneas excesivas para considerar que delimitan aguas interiores.

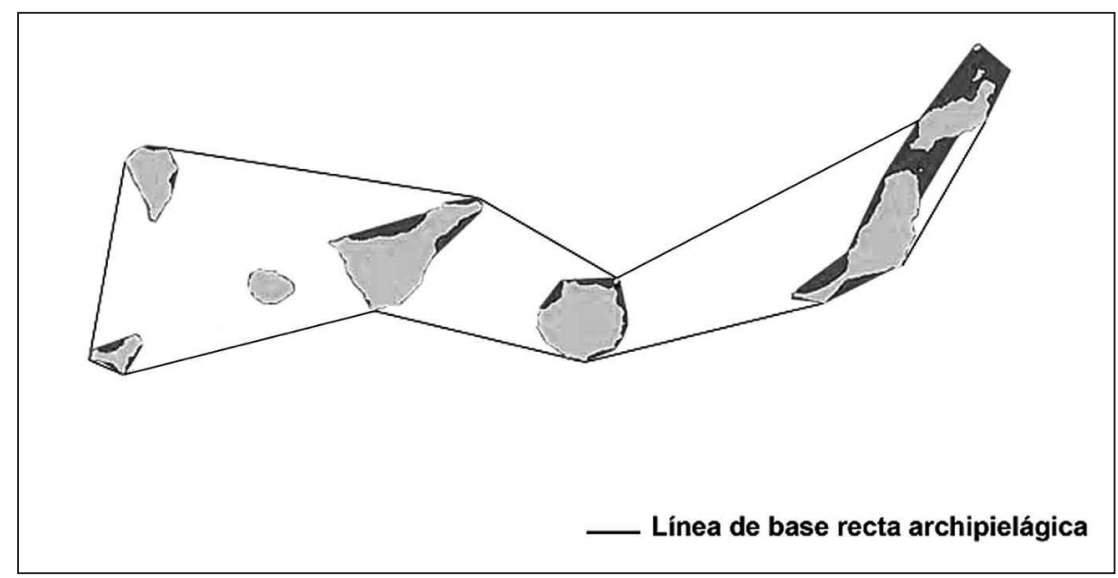

FUENTE: ELABORACIÓN PROPIA.

otros Estados, pero significaría una aportación sustancial a la identidad de la Comunidad Autónoma al contemplar al mar como parte de su territorio».

${ }^{60}$ El último párrafo de la Exposición de Motivos de la proposición de 2009 señalaba: «si bien la Convención de las Naciones Unidas sobre el Derecho del Mar, celebrada en 1982 en Montego Bay, Jamaica dedica una parte a la aplicación del régimen de delimitación de los distintos espacios marítimos de acuerdo con el método de las líneas de bases rectas a los Estados Archipielágicos, ello no impide que ese método también pueda ser aplicado, conforme con el régimen general de delimitación recogido en dicha Convención, a los Estados mixtos o Archipiélagos de Estado, que es el caso de Canarias, como efectivamente lo han realizado diversos países», véase el Boletín Oficial de las Cortes Generales no 195-1, de 4 de septiembre de 2009. 
La Ley 44/2010, en el párrafo segundo del artículo único también hace una breve referencia al reparto interno de competencias entre el Estado y la Comunidad Autónoma de Canarias sobre esos espacios ${ }^{61}$. La disposición final primera faculta al Gobierno para dictar las disposiciones reglamentarias necesarias para desarrollar la ley, previo informe del Gobierno de Canarias.

Además, hay que recordar nuevamente que esta cuestión también formaba parte de la proposición de reforma del Estatuto de Autonomía de Canarias de 2006 y que ya fue mencionada anteriormente. Hay un alto grado de consenso político alrededor de este asunto entre las fuerzas políticas presentes en las Islas (véase como ejemplo el debate y la votación unánime de toma en consideración de la proposición de ley de diciembre de 2009), por ello, es muy previsible que en la próxima proposición de reforma del Estatuto que se envíe a las Cortes Generales volverá a figurar. No obstante, la Ley 44/2010 no obtuvo el voto favorable del Partido Popular ${ }^{62}$.

La declaración unilateral ${ }^{63}$ de España estableciendo el criterio de delimitación archipielágico de líneas de base recta a los espacios marítimos de Canarias es previsible que no se encuentre con la aquiescencia de otros Estados.

Debemos tener en cuenta que Canarias es un archipiélago cuyos espacios marítimos colisionan con países vecinos. Es sabido que España mantiene varios frentes abiertos con Marruecos por diversas disputas territoriales, por lo que sería ingenuo pensar que no habrá una protesta. Además, volvemos a recordar que está pendiente la cuestión de la soberanía sobre el Sáhara Occidental, que también se

${ }^{61}$ Para un análisis sobre el tema competencial interno véase González García (2002) y Torres Lana (2009).

${ }^{62}$ Entre las dos grandes fuerzas políticas nacionales hay reticencias de tipo jurídico. Así, en las anteriores legislaturas en las que hubo proposiciones similares, las iniciativas decayeron por la oposición final del grupo parlamentario mayoritario (PSOE o PP alternativamente) que sustentaba al Gobierno en cada ocasión, que siempre observaba un obstáculo jurídico insalvable en el Convenio de Montego Bay de 1982 al entender que sólo admite esta fórmula de delimitación de los espacios marítimos para los Estados Archipiélago. Para Lacleta Muñoz $(2005,6)$ se trata de una actitud comprensible puesto que las propuestas «iban dirigidas a que España realizara un acto contrario al Derecho Internacional establecido en la Convención de 1982. Es lógico que el Grupo Parlamentario del partido gubernamental no quisiera ver al Gobierno en tal situación». Por su parte, Rivero Alemán $(2001,33)$ acepta el obstáculo que supone el Derecho Internacional en la actual situación, pero, pese a ello, considera conveniente que España dé ese paso unilateral en la línea de otros Estados mixtos.

${ }^{63}$ Kriele $(1980,127)$ advierte que «Si bien el territorio del Estado está constituido no por datos fácticos — geográficos o nacionales — sino por estipulación jurídica, tal cosa no quiere decir, sin 
vería afectado. También, como vimos anteriormente, existe conflicto con Portugal sobre la delimitación de la ZEE entre Madeira y Canarias (básicamente por el efecto de las Islas Salvajes), aunque, dado que Portugal comparte con España su interés en la aplicación más favorable a los Archipiélagos de Estado, no se prevé un importante obstáculo con los lusos.

Por otro lado, también hay que reseñar que Canarias, a diferencia de los casos de Galápagos, Feroe, Spitzberg o Houtman, se encuentra en una zona de intenso tráfico marítimo por estar en medio de importantes rutas internacionales ${ }^{64} \mathrm{y}$ por constituir una plataforma en un contexto geopolítico de gran interés ${ }^{65}$. Por tanto, es previsible que afloren los intereses de las grandes potencias y otros Estados con flotas relevantes como ya ocurriera en los trabajos de elaboración de la Convención de Montego Bay.

En todo caso, sin tener que llegar a dar el salto cualitativo que supondría dar efectos frente a terceros Estados a los criterios delimitadores de la Ley 44/2010 y tomar la senda del acto unilateral, como ya han hecho otros países aunque en contextos menos conflictivos, existen otras formas de lograr avances para la salvaguarda de los intereses que se quieren defender en Canarias en torno a esos espacios marítimos ${ }^{66}$.

Probablemente, la actual situación jurídica que permite un intenso control por parte del Estado en el mar territorial, a muchos de los efectos de lo reclamado

embargo, que esta constitución se opere en forma unilateral por la fuerza creadora del derecho del poder estatal. El territorio del Estado no puede ser una función del poder del Estado y no puede ser fijado por el derecho estatal, porque toda estipulación de frontera afecta a los vecinos y las estipulaciones unilaterales provocarían conflictos. El curso de la frontera del territorio del Estado, es, por tanto, una cuestión del derecho internacional. La situación fáctica sólo es decisiva si no fue atacada por los vecinos. Si se la ataca, entonces el conflicto sólo puede ser resuelto pacíficamente mediante una estipulación contractual de las fronteras».

${ }^{64}$ Segura Clavell $(2008,159$ y ss.) señala que Canarias está en la ruta de los petroleros que proceden del Cabo de Buena Esperanza y transportan petróleo para Europa, así como buques de transporte de mercancías. Este movimiento es superior a los 35.000 anualmente, sin contar con los que tienen su punto de llegada o salida en alguno de los puertos de Canarias.

${ }^{65}$ Martín Ruiz $(2005,10)$ destaca la aventajada posición geopolítica de Canarias y que, desde la entrada de España en la OTAN en 1986, «ha posibilitado la ampliación de su espacio político y militar hacia el sur, esto es, hacia el atlántico medio e incluso meridional pudiendo de esta manera controlar el territorio africano».

${ }^{66}$ En la intervención del diputado de Coalición Canaria Perestelo Rodríguez en la defensa de la toma en consideración de la proposición de ley en diciembre de 2009, se resume las principales razones, compartidas por la práctica totalidad de las formaciones políticas en Canarias, para sostener la necesidad de un mayor control de las aguas interinsulares: «No es concebible que a estas alturas ni España ni Canarias tengan pleno control sobre este espacio marítimo interinsular en unos tiempos en los que crece la amenaza medioambiental por vertidos o pesca abusiva, aumenta la inseguridad por el tráfico clandestino de personas, drogas y armas, y se extiende el terrorismo global. (...) No es por mas tiempo tolerable que a día de hoy cualquier tipo de tráfico marítimo pueda sur- 
anteriormente también en la zona contigua, y en los asuntos económicos también sobre la ZEE, facilita ahora mismo un margen de acción al Estado que podría ser más intenso; sin perjuicio de admitir que sería algo más amplio si todos esos espacios se midieran desde el perímetro archipielágico ${ }^{67}$.

Una especial atención merece lo relativo al control del intenso tráfico marítimo de tránsito entre las Islas y su incidencia medioambiental, que tanto preocupa en una Comunidad Autónoma dependiente de su imagen, biodiversidad y patrimonio natural que posibilita que el turismo (mayoritariamente de playa y mar) sea la principal y destacada actividad económica ${ }^{68}$. Anteriormente se mencionó la importante presencia de buques tanques de crudo, más aún tras la explotación de los pozos del Golfo de Guinea (Nigeria, Guinea Ecuatorial, etc.) que se une al triste recuerdo de casos como los del Exxon Valdez o el Prestige. La propia Convención del Derecho del Mar de 1982 (arts.65 y 194) buscan favorecer las medidas para evitar la contaminación del medio marino, pero es el Convenio Internacional para Prevenir la Contaminación por los Buques ${ }^{69}$ el que específicamente prevé la delimitación de áreas especiales, por sus condiciones oceanográficas y ecológicas. Este Convenio permite que las zonas especiales declaradas Zona Marítima Especialmente Sensible tengan una protección acordada por la Organización Marítima Internacional que, entre otras medidas de control, permite establecer limitaciones al tráfico de buques con mercancías peligrosas y desviarlos por determinadas rutas ${ }^{70}$. La aprobación provisional de Canarias como $Z_{M E S}^{71}$ se produjo en 2004, con la oposición de varias potencias petroleras (Liberia, Panamá, EE.UU o Rusia), y entró en vigor el 1 de diciembre de 2006. El nuevo status de Canarias como

car las aguas interinsulares canarias sin que podamos objetar lo más mínimo con el derecho en la mano», véase Diario del Congreso de los Diputados n ${ }^{\circ} 131$ de 15 de diciembre de 2009.

${ }^{67}$ Baeza Betancort $(1987,39$ y ss.) advierte que, en todo caso, la aplicación del principio archipielágico a Canarias tiene escasas ventajas prácticas puesto que sólo se obtienen una pocas millas más al solaparse las zonas generadas por cada una de las Islas.

${ }^{68}$ Sobre la protección medioambiental del medio marino véase la reciente Ley 41/2010, de 29 de diciembre (BOE $\mathrm{n}^{\circ} 317$ de 30 de diciembre), que realiza la trasposición de la Directiva 2008/56/CE, de 17 de junio de 2008, que establece un marco de acción comunitaria para la política del medio marino.

${ }^{69}$ Este Convenio fue firmado por España en 1979 y ratificado 1984, es comúnmente conocido como MARPOL (Mar Pollution).

${ }^{70}$ Véase Segura Clavell (2008, 156 y ss.).

${ }^{71}$ Para un estudio del proceso de declaración de Canarias como ZMES véase Cenzual Miñano (2008). Para una información exacta de la zona delimitada, medidas tomadas, procedimientos, etc. véase la página de Internet de la Asociación Canaria de Oficiales de la Marina Mercante www.oficialesdelamarinamercante.com/zmescanarias.html (consultada enero de 2010). 
ZMES ha permitido que se restrinja el tráfico de buques con hidrocarburos, mercancías peligrosas o contaminantes ${ }^{72}$ a dos rutas definidas de tránsito interinsular, una entre Tenerife y Gran Canaria y otra entre Gran Canaria y Fuerteventura, aunque lo ideal habría sido desviar a esos buques en tránsito a más de 20 millas al oeste de las costas más occidentales del Archipiélago, impidiendo, por tanto, el paso interinsular.

\section{CONCLUSIONES}

El Convenio Internacional de Montego Bay de 1982, aplicable para España desde 1997 sin reservas, establece un régimen jurídico para las aguas interinsulares de los Archipiélagos de Estado que les discrimina respecto a los Estados Archipielágicos al no permitirles establecer el sistema de líneas de base rectas archipielágicas.

Pese a lo anterior, varios Estados mixtos (formados por territorio continental y archipiélagos) han decidido, unilateralmente, establecer, total o parcialmente, el régimen de líneas de base rectas archipielágicas para sus archipiélagos (Ecuador con las Islas Galápagos, Dinamarca con las Islas Feroe, Noruega con el Archipiélago Spitzberg o Svalvard, Australia con las Islas Houtman o Portugal, parcialmente, con Madeira y Azores).

La nueva Ley 44/2010 de Aguas Canarias supone una manifestación política de intenciones de España que ya exterioriza la voluntad de pretender utilizar el criterio de delimitación de la línea de base recta archipielágica; sin embargo, la Ley excluye expresamente que se quiera modificar el régimen jurídico internacional vigente. Por lo tanto, por el momento, se trata de una norma que carece de eficacia jurídica. Es previsible que la próxima iniciativa de reforma estatutaria vuelva a plantear la cuestión de la delimitación de los espacios marítimos en torno a las Islas Canarias.

La eventual declaración unilateral de España de la aplicación del sistema de líneas de base recta archipielágica en Canarias (enclavadas en una zona de intenso tráfico de buques mercantes y petroleros), bien mediante una Ley estatal específica, o bien mediante una Ley Orgánica de aprobación de un Estatuto de Autonomía para Canarias, es muy probable que encuentre la oposición de las grandes potencias marítimas (en particular de EE.UU.) y del vecino Marruecos, con quien España mantiene varios contenciosos territoriales.

${ }^{72}$ Véase también el Reglamento CE 417/2002 del Parlamento Europeo y del Consejo relativo a la introducción acelerada de normas en materia de doble casco o de diseño equivalente para petroleros de caso único (ésta y otra normativa europea concordante en Pulido Begines, 2009, 86 y ss.). 
A los efectos de incrementar la seguridad y de lograr un mayor control del tráfico marítimo por razones medioambientales, resulta necesario que en Canarias se puedan aplicar con rigurosidad las opciones que permite el régimen jurídico de la zona contigua (hasta 24 millas desde cada isla) y buscar la complementariedad de opciones como la declaración definitiva de Zona Marítima de Especial Sensibilidad.

\section{BIBLIOGRAFÍA:}

ALZAGA VILlAAMIL, Óscar (2007): Derecho Politico Español, vol.1. CERA, Madrid.

ARROYO LARA, Eladio (1981): «El problema de la delimitación de los espacios marítimos en el archipiélago canario», en Anuario de Derecho Marítimo $n^{\circ}$ 6, pp. 173-182.

BAEZA BETANCORT, F. (1987): Las Islas Canarias ante el nuevo Derecho Internacional del Mar, Las Palmas.

CENZUAL MIÑANO, Javier (2008): Designación de Canarias como Zona Marítima de Especial Sensibilidad, Idea, Las Palmas de G.C.

DÍAZ NIEVA, José (1997): «El Estado: concepto y elementos», en Manual de Derecho Constitucional vol. I, VV.AA. Colex, Madrid, pp. 15-34.

DÍEZ-PICAZO, Luis María (1987): «Sobre la delimitación estatutaria del territorio de las Comunidades Autónomas y la rigidez de los Estatutos», en Revista Española de Derecho Constitucional, $n^{\circ} 20$, pp. 139-177.

DÍEZ DE VELASCO, Manuel (2009): Instituciones de Derecho Internacional Público, Tecnos, Madrid.

GÓMEZ-ROBLEDO VERDUZCO, A. (1998): «Métodos de delimitación en Derecho del Mar y el problema de las islas», en Boletín Mexicano de Derecho Comparado, 93. Pp.639-711.

GONZÁLEZ CAMPOS, Julio, SÁNCHEZ RODRÍGUEZ, Luis y SÁENZ DE SANTAMARÍA, Paz Andrés (2008): Curso de Derecho Internacional Público, Thomson, Civitas, Aranzadi, Pamplona.

GONZÁLEZ GARCÍA, Julio V. (2002): «Las aguas bajo soberanía o jurisdicción del Estado español y las competencias de las Comunidades Autónomas, en Revista de Administración Pública n $n^{\circ}$ 158. Pp. 51-76.

GROCIO, Hugo (1979): De la libertad de los mares, Centro de Estudios Constitucionales (traducción del original de 1609), Madrid.

JELLINEK, Georg (2000): Teoría General del Estado, traducción al español de Edit. Fondo de Cultura Económica (original de 1905), México. 
KELSEN, Hans (1989): Il problema della souranità, traducción al italiano de Edit. Giuffrè (original de 1920), Milano.

KELSEN, Hans (2002): Teoría General del Estado, traducción al español de Edit. Comares (original de 1925), Granada.

KRIELE, Martin (1980): Introducción a la Teoría del Estado, traducción de Edit. Depalma (original de 1975), Buenos Aires.

LACLETA MUÑOZ, José Manuel (2003): «Las aguas españolas en la costa africana», Conferencia pronunciada en la Semana de Estudios del Mar de la Asociación de Estudios del Mar celebrada en octubre de 2003 en Melilla (disponible en www.reei.org).

LACLETA MUÑOZ, José Manuel (2005): «Las aguas del archipiélago canario en el Derecho Internacional del mar actualmente vigente», en Documento de Trabajo 31/2005 del Real Instituto Elcano de Estudios Internacionales y Estratégicos, Madrid.

LACLETA MUÑOZ, José Manuel, ALMAZÁN GÁRATE, José Luis y ESTEPA MONTERO, Manuel (2009): El régimen jurídico de los espacios marinos en el Derecho Español e Internacional, Colegio de Ingenieros de Caminos, Canales y Puertos, Madrid.

LÓPEZ LABORDA, Julio (2010): «El nuevo modelo de financiación de las Comunidades Autónomas», en La reforma del sistema de financiación de las Comunidades Autónomas, CEPC. Pp. 151-173.

MARTÍN RUIZ, Juan F. (2005): «Los espacios marítimos y el problema de su delimitación en la posición geopolítica del Archipiélago canario» en Geo Crítica I Scripta Nova. Revista electrónica de geografía y ciencias sociales. Barcelona: Universidad de Barcelona, 15 de marzo de 2005, vol. IX, núm. 185. (Disponible en http://www.ub.es/geocrit/sn/sn-185.htm, consultada diciembre 2009)

MORALES MORILLAS, Carlos (2002): «La condición jurídica de los espacios marítimos de Canarias: problemática actual», en Anales de la Facultad de Derecho $n^{\circ}$ 19, Universidad de La Laguna. Pp. 117-137.

ORIHUELA, Esperanza (1985): «Las Islas y Archipiélagos españoles en la delimitación de espacios marinos», en Anuario de Derecho Internacional $n^{\circ}$ VII, EUNSA, Pamplona. Pp. 337-358.

PULIDO BEGINES, Juan Luis (2009): Instituciones de Derecho de la Navegación, Tecnos, Madrid.

RODRÍGUEZ DOMÍNGUEZ, Carlos (2006): Análisis jurídico internacional de la delimitación de las aguas canarias», en Anales de la Facultad de Derecho $n^{\circ}$ 23, Universidad de La Laguna. Pp. 157-175.

RIVERO ALEMÁN, Santiago (2001): «El archipiélago canario y la delimitación de sus aguas marítimas», en Pórtico Legal (Disponible en http://www.porticolegal.com/pa articulo.php? $r e f=168$ ). 
RUILOBA GARCÍA, Eloy (2009): «La delimitación equitativa de los espacios marítimos de los archipiélagos de Estado en Derecho Internacional», en Revista Jurídica de Canarias $n^{\circ} 14$. Pp. 479-496.

SANTAMARÍA PASTOR, Juan Alfonso (2001): «Territorio», voz del diccionario enciclopédico Temas Básicos de Derecho Constitucional, vol. 1, coord. Manuel Aragón Reyes, Civitas, Madrid.

SÁNCHEZ FERRIZ, Remedio (2009): El Estado Constitucional. Configuración bistórica y jurídica. Organización funcional, Tirant lo Blanch, Valencia.

SEGURA CLAVELL, José (2008): «La necesidad de una política marítima española integrada en la Unión Europea», en Revista de las Cortes Generales $n^{0}$ 74. Pp.105-190.

TENORIO SÁNCHEZ, Pedro J. (1993): «El Estado. Concepto. Elementos», en Introducción al Derecho Político, dir. Torres del Moral. UNED, Madrid, pp. 9- 30.

TORRES LANA, José Javier (2009): «Canarias, Archipiélago Atlántico. Los hechos diferenciales», en Revista Jurídica de Canarias n 13. Pp. 509-538.

TORRES DEL MORAL, Antonio (2004): Estado de Derecho y democracia de partidos, Servicio de Publicaciones de la Facultad de Derecho de la Universidad Complutense, Madrid.

YTURRIAGA BARBERÁN, José Antonio (1993): Ámbitos de soberanía en la Convención de las Naciones Unidas sobre el Derecho del Mar (una perspectiva española), Ministerio de Asuntos Exteriores, Madrid.

Title

LEGAL PROBLEMS ON THE DELIMITATION OF SEA SPACE OF THE CANARY ISLANDS (A PURPOSE THE 44/2010 LAW)

\section{Summary:}

I. INTRODUCTION TO THE CONCEPT OF TERRITORY AS AN ELEMENT OF THE STATE. II. CONCEPTUAL LIMITS OF SEA SPACE. III. PECULIARITIES OF SEA DEMARCATION IN ISLANDS AND ARCHIPELAGOS: SINGULARITIES OF THE CANARY ISLANDS. III. 1. Sea space between islands in archipelagic states and archipelagos of state. III.2. Specific problems for the delimitation of territorial waters of the Canary Islands. III.3. The case of other archipelagos of state in Comparative Law. III.4. Problems for the delimitation of other sea spaces around the Canary Islands: a) The delimitation with Morocco, b) The delimitation with the Portuguese islands. III.5. Recent proposals on the problems for the delimitation of Canarias sea spaces. The 44/2010 Law. IV. CONCLUSIONS. Bibliography. 


\section{Resumen:}

Una de las obligaciones de los Estados es determinar el espacio físico de validez de su ordenamiento jurídico y, en caso de conflictivos sobre las fronteras, será necesario acudir a las normas de Derecho Internacional. Especialmente conflictivo suele ser la determinación de los espacios marítimos sobre los que el Estado pretende proyectar algún tipo de control, no sólo por afectar a otros Estados vecinos, sino también a los intereses de terceros sobre estos espacios: derechos de navegación, de explotación de recursos naturales. La situación de los territorios archipielágicos presenta un régimen muy particular según el Convenio de Montego Bay y que perjudica los intereses de los archipiélagos de Estado como Canarias. Por este motivo, es conveniente realizar un análisis de la viabilidad de las alternativas jurídicas que existen para las Islas Canarias, en particular de la Ley 44/2010.

\section{Abstract:}

One of the obligations of the states is to determine the physical space on which their legal systems act and, in case of coming into conflict over borders, it will be necessary to turn to the rules of the international law. Especially controversial is often the determination of the band of sea over which the state expects to have certain rights as it does not only affect other neighbouring states, but also the interests of third parties in these areas: navigation right, the right to exploit the natural resources. The status of the archipelagic territories presents a very particular regulation under the Convention of Montego Bay, that is against the interests of the archipelagos of state, such as the Canary Islands. By this reason, it's convenient to analyse the juridical options to Canary Islands, specially about Ley 44/2010.

\section{Palabras clave:}

Archipélagos de Estado, Estados Archipielágicos, aguas marítimas, soberanía marítima

\section{Keywords:}

Archipelagos of state, archipelagic states, territorial waters, sea sovereignity 